Asymmetric and Non-atmospheric Consumption Externalities, and Efficient Consumption Taxation

by

Paul Eckerstorfer and Ronald Wendner

Working Paper No. 1301

January, 2013

Johannes Kepler University of Linz

Department of Economics

Altenberger Strasse 69

A-4040 Linz - Auhof, Austria

www.econ.jku.at

paul.eckerstorfer@jku.at phone +43 (0)732 2468-8246, -9821 (fax) 


\title{
Asymmetric and Non-atmospheric Consumption Externalities, and Efficient Consumption Taxation*
}

\author{
Paul Eckerstorfer ${ }^{a}$ and Ronald Wendner $^{b}$ \\ ${ }^{a}$ Department of Economics, University of Linz, Austria \\ ${ }^{b}$ Department of Economics, University of Graz, Austria
}

January 16, 2013

\begin{abstract}
We analyze the effects of a generalized class of negative consumption externalities (asymmetric and non-atmospheric) on the structure of efficient commodity tax programs. Households are not only concerned about consumption reference levels - that is, they gain utility from "keeping up with the Joneses" they also exhibit altruism. Two sets of efficient tax regimes are compared, based, on a welfarist- and a non-welfarist optimality criterion, respectively. Altruism turns out not to be at odds with the consumption externalities. Rather, altruism implicates a bound on efficient utility allocations. A non-welfarist government tolerates less inequality than a welfarist one. In the welfarist (non-welfarist) case, first-best personalized commodity tax rates respond highly sensitively (barely) to whether or not a consumption externality is asymmetric or non-atmospheric. If personalized commodity tax rates are not available (second-best case), the tax rate on a nonpositional good is typically different from zero for corrective reasons. For plausible functional forms and parameter values, numerical simulations suggest that secondbest tax rates are rather insensitive with respect to both the optimality criterion and the "nature" of the consumption externality.
\end{abstract}

Keywords and Phrases: Consumption externality, keeping up with the Joneses, optimal (commodity) taxation, genuine altruism, non-welfarist government.

JEL Classification Numbers: D62, H21, H23

${ }^{\star}$ We thank Johann K. Brunner and Susanne Pech for significant comments on a previous draft. However, we retain sole responsibility for any remaining errors.

Corresponding author: Ronald Wendner, ronald.wendner@uni-graz.at. 
Since ... appearance tyrannizes over truth and is lord of happiness, to appearance I must devote myself.

- Plato, The Republic (Book II)

\section{Introduction}

This paper addresses the effects of a generalized class of negative consumption externalities (asymmetric and non-atmospheric) on the structure of efficient commodity taxation in a framework with both a positional and a non-positional commodity. That is, individual utility is not independent of other individuals' consumption. In fact, households form consumption reference levels, a fact well established in the literature (cf. the discussion below). Consumption reference levels give rise to a consumption externality. This externality is often referred to as a keeping up with the Joneses externality. ${ }^{1}$

In contrast to the prior literature, the present analysis takes three important facts into account. First, some people typically contribute more to a consumption reference level than others. In this case, we refer to the consumption externality as a non-atmospheric one. In other words, not every household belongs to one's consumption reference group (to the same degree). ${ }^{2}$ In contrast, a consumption externality is termed atmospheric if consumption of the positional commodity of any two households are perfect substitutes regarding the generation of one's consumption reference level. Second, consider the reference groups of two given households. Consumption of a member of both reference groups may exert different (asymmetric) effects on these two household's consumption reference levels - a situation we refer to as an asymmetric consumption externality. Third, households are not only concerned about consumption reference levels, they also exhibit altruism (cf. Johansson 1997).

This paper is motivated by the recent literature on consumption externalities and happiness. Psychologists and behavioral economists have established that indi-

\footnotetext{
${ }^{1}$ Different authors employ various terms, with slightly varying meanings. These terms include (negative) consumption externality, positional-, status-, relative consumption, jealousy, envy, catching up with the Joneses. As made precise below, we focus on the case of keeping up with the Joneses in this paper.

${ }^{2}$ For example, sometimes I see my neighbor next door drinking Nespresso. Other times, on TV, I see George Clooney drinking Nespresso. For some reason, one impresses me more than the other.
} 
viduals experience happiness by doing well relative to some reference group (Brekke and Howarth 2002, Easterlin 1995, Frank 1985, 1999). Important survey experimental studies substantiating this evidence include Johansson-Stenman et al. (2002, 2006), and Solnick and Hemenway $(1998,2005) .{ }^{3}$ The main response of economic theory to this evidence has regularly consisted in allowing for a uniform consumption reference term - commonly the economy's average consumption - in the utility functions of households. While consideration of the consumption reference level in an otherwise standard framework has delivered important insights ${ }^{4}$, the usual specification of "the" reference level still exhibits two major shortcomings.

The first shortcoming refers to a household's reference group(s). There may be different reference groups, and even within a reference group, some individuals may be considered more influential than others. For example, Cowan et al. (2004) argue that some activities become more desirable when they can be shared with a group of peers (peer group effect). Other activities become more desirable if they allow the consumer to emulate the consumption of an elite group that he or she aspires to join (aspiration effect). Still other activities become more desirable when the individual can, through wealth or personal endowments, out-shine its peers (distinction effect). In the jargon adopted in this paper, within a reference group, a household may be more concerned with some individuals rather than with others. That is, a consumption externality is usually non-atmospheric. In addition, the consumption of a given household might matter more for some individuals than for others, that is, a consumption externality commonly is asymmetric. Put differently, even if two households are concerned with the same reference group, this does not imply that these households also share the same consumption reference level.

The second shortcoming refers to the fact that households not only care about consumption reference levels but also about inequality or redistribution (Brekke and Howarth 2002). As has been shown, individuals dislike being "too different" from their peers. Fehr and Schmidt (1999), find that people dislike income inequality,

\footnotetext{
${ }^{3}$ A large number of further empirical studies add significant evidence. Cf. Alpizar et al. (2005), Alvarez-Cuadrado et al. (2012), Carlsson et al. (2007), Ferrer-i-Carbonell (2005), Luttmer (2005), Maurer et al. (2008), McBride (2001), Neumark et al. (1998), and Ravina (2007).

${ }^{4}$ Consumption externalities have shed light for example on the analysis of renewable resource extraction (Alvarez-Cuadrado and Van Long, 2011), envy and inequality (Van Long and AlvarezCuadrado, forthcoming), happiness (Easterlin 1995, Frank 1985, Frank 1999, Scitovsky 1992), economic growth (Brekke and Howarth 2002, Carroll et al. 1997, Liu and Turnovsky 2005), or asset pricing (Abel 1999, Campbell and Cochrane 1999, Dupor and Liu 2003).
} 
but they are more upset when their own income falls short than they are pleased by an excess in comparison to their reference levels.

In this paper, we take both of these shortcomings into account for the derivation of efficient tax programs under both a welfarist and a non-welfarist government. A welfarist government fully respects individual preferences in the formulation of the welfare criterion. On the other hand, a non-welfarist government does not tolerate status preferences - those are basically a form of envy - to be part of the welfare criterion. ${ }^{5}$ That is, in the non-welfarist case the government's and individuals' preferences differ. Our analysis sheds light on the optimal policies that emerge from these two different welfare criteria.

This paper is related to the prior literature on optimal taxation and consumption externalities (see, e.g., Aronsson and Johansson-Stenman 2008 and 2010, Boskin and Sheshinski 1978, Layard 1980, Ljungqvist and Uhlig 2000). From this literature it is well established that an externality due to relative consumption concerns calls for some corrective element in the tax system. For example, Aronsson and JohanssonStenman (2008) show that the presence of a keeping up with the Joneses externality implies substantially higher marginal income tax rates. The issue of a consumption externality being non-atmospheric rather than atmospheric has also already been taken up by Eckerstorfer (2013), Micheletto (2008) and Wendner (2013). From these studies it has become evident that the nature of a consumption externality indeed matters for the optimal tax structure. However, this literature does not consider asymmetric consumption externalities. Our paper is also related to the literature that studies optimal tax policy from the perspective of a non-welfarist government (see, e.g., Besley 1988, Blomquist and Micheletto 2006, O’Donoghue and Rabin 2006). These studies are concerned with the taxation of sin goods and (de)merit goods where the government does not fully respect households' preferences.

This paper explicates four results. First, efficient welfarist first-best tax rates on the positional good are personalized and directly depend on the specific features of the non-atmospheric and asymmetric consumption externality. Specifically, households contributing more than others to the generation of the consumption externality face a higher first-best tax rate. However, in the non-welfarist case, efficient first-best tax rates directly depend on the specific features of the consumption exter-

\footnotetext{
${ }^{5}$ For example, Harsanyi (1982) claims that antisocial preferences such as envy or jealousy should not be allowed to be part of a social welfare function.
} 
nality only if the consumption reference level does have an impact on the marginal rate of substitution of the positional good for leisure. Second, if the consumption externality is non-atmospheric, the efficient corrective second-best tax rate on the non-positional good is generally different from zero, once a personalized tax on the positional good is not available. Third numerical simulations reveal that the first-best tax rates are highly sensitive with respect to the specific features of the consumption externality. In contrast, the second-best tax rates barely respond to the specific features of the consumption externality. Moreover, the second-best corrective tax rate on the non-positional good turns out to be quite low. Fourth, altruism and keeping up with the Joneses preferences are not contrasting motives - even if the consumption externality is non-atmospheric or asymmetric. Rather, altruism requires the distribution of utility not to bee too unequal, in a well-defined sense. It imposes a fairness condition which narrows the set of efficient allocations to those that are not too distant from an egalitarian allocation. The specific set of fair allocations is strongly affected by the features of the consumption externality. More inequality is tolerated towards households contributing more than others to the generation of the consumption externality. Moreover, for a given consumption externality, the set of fair allocations under a non-welfarist government is smaller than that under a welfarist government. A non-welfarist government tolerates less inequality compared to a welfarist government.

To sum up, the nature (non-atmospheric, asymmetric) of the consumption externality exhibits a strong impact on first-best commodity tax rates as well as on fair efficient utility allocations. While this is potentially also true in the secondbest, numerical simulations reveal that second-best tax rates are rather insensitive with respect to both the optimality criterion and the "nature" of the consumption externality. Altruism has no offsetting effect on the corrective elements in the tax system induced by the presence of status effects. However, altruism implies a fairness condition which requires the efficient distribution of utility not to be too unequal.

Section 2 of this paper presents the economy and defines non-atmospheric and asymmetric consumption externalities as well as the type of altruism adopted. It also characterizes a welfarist efficient first-best tax program. Section 3 discusses both a welfarist efficient second-best tax program (with uniform tax rates) and the 
impact of altruism on "fair" (utility) allocations. Section 4 considers efficient firstand second-best tax programs under a non-welfarist government. The efficient tax rates differ between the welfarist- and non-welfarist optimality criteria. Therefore, Section 5 presents numerical simulations in order to give a rough indication of the magnitude of the differences in efficient tax rates between the welfarist- and nonwelfarist cases. Section 6 concludes the paper. The appendix contains proofs and mathematical results that support the analysis of the main text.

\section{The model}

We consider a static economy with $n$ households. A household $i \in N=\{1, \ldots, n\}$ has preferences over two private goods $x_{i}$ and $z_{i}$, leisure $l_{i}$ and a reference consumption level $\bar{z}_{i}$. In addition, households derive utility from the average utility of all households in the economy. We consider spending on $x$ as a nonpositional form of consumption and spending on $z$ as status consumption, i.e. for good $z$ households care about their relative consumption with respect to others. Households differ in their exogenous earning ability $w_{i}$ and in their preferences. The preferences of a household are represented by the concave utility function

$$
u_{i}\left(x_{i}, z_{i}, l_{i}, \bar{z}_{i}\right)+\frac{\varphi}{n} \sum_{j=1}^{n} u_{j}\left(x_{j}, z_{j}, l_{j}, \bar{z}_{j}\right),
$$

where $\varphi \geq 0$ is a weighting factor which is assumed to be constant across households. Utility of a household $i$ increases in own private consumption and leisure and decreases in the reference level $\overline{z_{i}}$. Further, similarly to Brekke and Howarth (2002) utility of a household increases with the average utility of the whole population, i.e. households are altruistic as they also derive satisfaction from the general welfare in the economy. ${ }^{6}$ The strength of altruism is reflected by $\varphi$. Both the reference level and the average utility of all households are considered to be exogenous by a household. ${ }^{7}$

The consumption reference level $\overline{z_{i}}$ gives rise to a negative consumption externality. In this paper, we focus on the case of a keeping up with the Joneses (KUJ-) externality. Dupor and Liu (2003) define preferences exhibiting a KUJ externality

\footnotetext{
${ }^{6}$ Johansson (1997) refers to this form of altruism as genuine altruism.

${ }^{7}$ Intuitively a household considers her own contribution to the reference level and to the average utility in the population as extremely small and therefore negligible.
} 
by $\partial\left(u_{z} / u_{l}\right) / \partial \bar{z}>0 .{ }^{8}$ That is, we assume that the marginal utility of consuming the status good relative to that of leisure increases in the reference level.

Let the reference level of a household $i$ concerning consumption of good $z$ be determined by

$$
\bar{z}_{i}=\frac{1}{n} \sum_{j=1}^{n} a_{i j} z_{j} .
$$

with $i, j \in N$. The nonnegative coefficient $a_{i j}$ indicates the amount by which the consumption of one unit of the status good, $z$, by the externality-generating household $j$ raises the consumption reference level of household $i$. Thus, regarding the composition of $\overline{z_{i}}$, the second index of coefficients $a_{i j}$ refers to the household of origin of the consumption externality, and the first index of coefficients $a_{i j}$ refers to the household of destination of the consumption externality. If $a_{i j}=1$ for all $i, j \in$ $N$ the reference level is equal to the economy's mean consumption of the status good. However, in general these weights differ between different households of origin $\left(a_{i j} \neq\right.$ $a_{i j^{\prime}}$ with $i, j, j^{\prime} \in N$ and $j \neq j^{\prime}$ ) and between different households of destination $\left(a_{i j} \neq a_{i^{\prime} j}\right.$ with $i, i^{\prime}, j \in N$ and $\left.i \neq i^{\prime}\right)$. This gives rise to two forms of heterogeneities in the reference level. First, if weights differ between households of origin a given consumption quantity of some households contributes more to the consumption reference levels than the same consumption quantity of other households. Second, if weights differ between households of destination, different households, in general, have different reference levels.

We say that an externality is of the atmospheric type if weights are constant across all households of origin. In contrast, if weights differ across households of origin, then the externality is said to be of the non-atmospheric type.

\section{Definition 1 (Non-atmospheric consumption externality)}

An externality is said to be non-atmospheric if $a_{i j} \neq a_{i j^{\prime}}$ for some $i, j, j^{\prime} \in N$ with $j \neq j^{\prime}$. Otherwise it is atmospheric.

If an externality is non-atmospheric, the status consumption $\left(z_{j}, z_{j^{\prime}}\right)$ of households $j$ and $j^{\prime}$ are not perfect substitutes regarding the generation of $\overline{z_{i}}$. Assume that $N_{H} \subset N$ represents the set of all households with a "high" social status. If the reference consumption levels depend only on the consumption of members of this

\footnotetext{
${ }^{8}$ We use subscripts to denote partial derivatives with respect to the subscripted variable, that is $u_{z}=\partial u / \partial z$. Subscripts $i, j$ refer to households (rather than being partial derivatives).
} 
group, then $a_{i j}>0$ if $j \in N_{H}$ and $a_{i j}=0$ if $j \notin N_{H}$ for all $i \in N$.

We say that an externality is symmetric if weights are constant across households of destination. In contrast, we say that an externality is asymmetric if weights differ between households of destination.

\section{Definition 2 (Asymmetric consumption externality)}

An externality is said to be asymmetric if $a_{i j} \neq a_{i^{\prime} j}$ for some $i, i^{\prime}, j \in N$ with $i \neq i^{\prime}$. Otherwise, it is symmetric.

As long as $a_{i j}=a_{i^{\prime} j}$ for all $i, i^{\prime}, j \in N, \overline{z_{i}}=\overline{z_{i^{\prime}}}$. That is, as long as the externality is symmetric, there is a unique reference level for the whole population. Only if the externality is asymmetric, households have different reference levels, no matter whether the externality is non-atmospheric or not:

\section{Lemma 1 (Asymmetric and non-atmospheric consumption externality)}

An asymmetric consumption externality implies personalized consumption reference levels, irrespective of whether the consumption externality is of the non-atmospheric type or not.

There is a linear technology for the production of private goods with labor as the only input. Quantities of goods are chosen such that the (constant) marginal costs of production are equal to one for all commodities. Given competitive markets, the producer prices of both commodities equal one and the wage rate of a household $i$ equals productivity $w_{i}$. The time endowment of a household is normalized to one and is divided between labor and leisure. Hence, the labor income of a household is given by $w_{i}\left(1-l_{i}\right)$.

\subsection{The household's maximization problem}

In a first step, we characterize consumer behavior given competitive markets. Households maximize their utility subject to the private budget constraint

$$
q_{x} x_{i}+q_{z} z_{i} \leq w_{i}\left(1-l_{i}\right)+\tau_{i}
$$

where $q_{x}=1+t_{x}$ and $q_{z}=1+t_{z}$ are consumer prices and $\tau_{i}$ is a lump-sum transfer. The tax instruments of the government consist of proportional commodity taxes $t_{x}$ 
and $t_{z}$ and a lump-sum element $\tau_{i} \cdot{ }^{9}$ Labor income is left untaxed without loss of generality.

Households choose consumption and leisure such that the following necessary conditions hold:

$$
\begin{aligned}
-M R S_{z x}^{i} & =\frac{1+t_{z}}{1+t_{x}}, \\
-M R S_{l x}^{i} & =\frac{w_{i}}{1+t_{x}},
\end{aligned}
$$

with $M R S_{k x} \equiv-u_{k} / u_{x}$ and $k \in\{z, l\}$. Households choose $x, z, l$ so as to equalize their marginal rates of substitution to relative prices. Observe that the altruism parameter $\varphi$ does not appear in these optimality conditions, i.e. the presence of altruism has no effect on the consumption and leisure decision of a household. A household's indirect utility function is given by

$$
v_{i}\left(q_{x}, q_{z}, \tau_{i}, \bar{z}_{i}\right)+\frac{\varphi}{n} \sum_{j=1}^{n} v_{j}\left(q_{x}, q_{z}, \tau_{j}, \bar{z}_{j}\right)
$$

It is the maximum utility a household $i$ can obtain, given consumer prices, the lump-sum transfer and the reference level. Observe that due to the presence of altruism the indirect utility of household $i$ also depends on the lump-sum element and reference level of all other households.

\subsection{Characterization of a first-best allocation}

In this subsection we characterize first-best allocations for this economy and analyze which tax instruments are required to implement these allocations. Assume that a social planner can directly determine $x_{i}, z_{i}, l_{i}$ for each household $i$. Then a Pareto efficient first-best allocation is a solution to the following problem:

$$
\max _{x_{i}, z_{i}, l_{i}, \bar{z}_{i}, i=1, \ldots, n} u_{1}\left(x_{1}, z_{1}, l_{1}, \bar{z}_{1}\right)+\frac{\varphi}{n} \sum_{j=1}^{n} u_{j}\left(x_{j}, z_{j}, l_{j}, \bar{z}_{j}\right)
$$

\footnotetext{
${ }^{9}$ In first-best we allow the tax rate on the status good to vary across households, i.e. we allow for personalized commodity taxes $t_{z, i}$, and hence, for personalized consumer prices $q_{z, i}$.
} 
subject to

$$
\begin{array}{ll}
u_{i}\left(x_{i}, z_{i}, l_{i}, \bar{z}_{i}\right)+\frac{\varphi}{n} \sum_{j=1}^{n} u_{j}\left(x_{j}, z_{j}, l_{j}, \bar{z}_{j}\right) \geq \bar{u}_{i} \quad i=2, \ldots, n & \left(\mu_{i}^{F B}\right) \\
\sum_{i=1}^{n} x_{i}+\sum_{i=1}^{n} z_{i}=\sum_{i=1}^{n} w_{i}\left(1-l_{i}\right) & \left(\lambda^{F B}\right) \\
\bar{z}_{i}=\frac{1}{n} \sum_{j=1}^{n} a_{i j} z_{j} & i=1, \ldots, n \quad\left(\gamma_{i}^{F B}\right)
\end{array}
$$

where $\bar{u}_{i}$ is some minimum utility requirement for household $i$. Lagrange multipliers are given within parenthesis and the index FB refers to first-best. By varying the minimum utility requirement $\bar{u}_{i}$ the family of Pareto efficient allocations can be characterized. In the Appendix we show that for an interior solution the following conditions hold:

$$
\begin{gathered}
-M R S_{z x}^{i}=1+\underbrace{\frac{\frac{1}{n} \sum_{j=1}^{n} \gamma_{j}^{F B} a_{j i}}{\lambda^{F B}}}_{\Psi_{i}} \\
-M R S_{l x}^{i}=w_{i} \\
\frac{1+\varphi}{\varphi} \geq \frac{1}{n} \sum_{j=1}^{n} \frac{\partial u_{i} / \partial x_{i}}{\partial u_{j} / \partial x_{j}}
\end{gathered}
$$

for $i=1, \ldots, n$. Equations (11) and (12) state conditions for an efficient allocation of consumption goods and leisure. Equation (13) is a fairness condition that puts a limit on the set of allocations consistent with the Pareto criterion.

The second term on the right-hand side of equation (11), which we call $\Psi_{i}$, represents a correction term that arises due to the existence of the status externality. It can be interpreted as the social harm that is caused by an additional unit of status good consumption of household $i$. It is strictly positive as utility decreases with an increase in the reference level. ${ }^{10}$ Observe that if the externality is non-atmospheric $\Psi_{i}$ differs between (some) households, i.e. $\Psi_{i} \neq \Psi_{i^{\prime}}$ if $a_{j i} \neq a_{j i^{\prime}}$ for $j, i, i^{\prime} \in N$ and $i \neq i^{\prime}$. Then, intuitively, status consumption of some households is at the margin socially more harmful than that of other households. Only if the externality is atmospheric $\Psi_{i}$ is constant across households. ${ }^{11}$

\footnotetext{
${ }^{10}$ It follows immediately from (55) that then each $\gamma_{j}^{F B}$ is strictly positive in the optimum.

${ }^{11}$ Note that even in this case households have different reference levels if the externality is asymmetric.
} 
The fairness condition in equation (13) shrinks the set of fair utility allocations. It is implied by the presence of genuine altruism in the utility function. ${ }^{12}$ It states that for an allocation to be Pareto efficient the average ratio of the marginal utility of consuming good $x$ between household $i$ and all (other) households must not be too large. This ratio is large if household $i$ consumes relatively little of good $x$ compared to all other households. In other words the fairness condition rules out allocations which are too unequal in terms of different marginal utilities of $x$ (and which would be Pareto efficient with purely egoistic preferences).

In Figure 1 we illustrate the fairness condition if there are only two types of households. ${ }^{13}$ One can see that the higher $\varphi$, the smaller the set of utility allocations consistent with the fairness condition. Specifically, for $\varphi=5$ all utility allocations on the segment $(\bar{A}, \underline{A})$ are consistent with the fairness condition. With $\varphi=15$, only the smaller segment $(\bar{B}, \underline{B})$ is consistent with the fairness condition. As the strength of altruism approaches infinity, the left hand side of (13) approaches unity. That is, $\partial u_{i}(.) / \partial x_{i}=1$, for all $i \in N$. Under strict quasi concavity of the individual utility functions, only a single utility allocation is consistent with the fairness condition. As the fairness condition requires equalization of marginal utilities, this singleton set need not correspond to an egalitarian utility allocation.

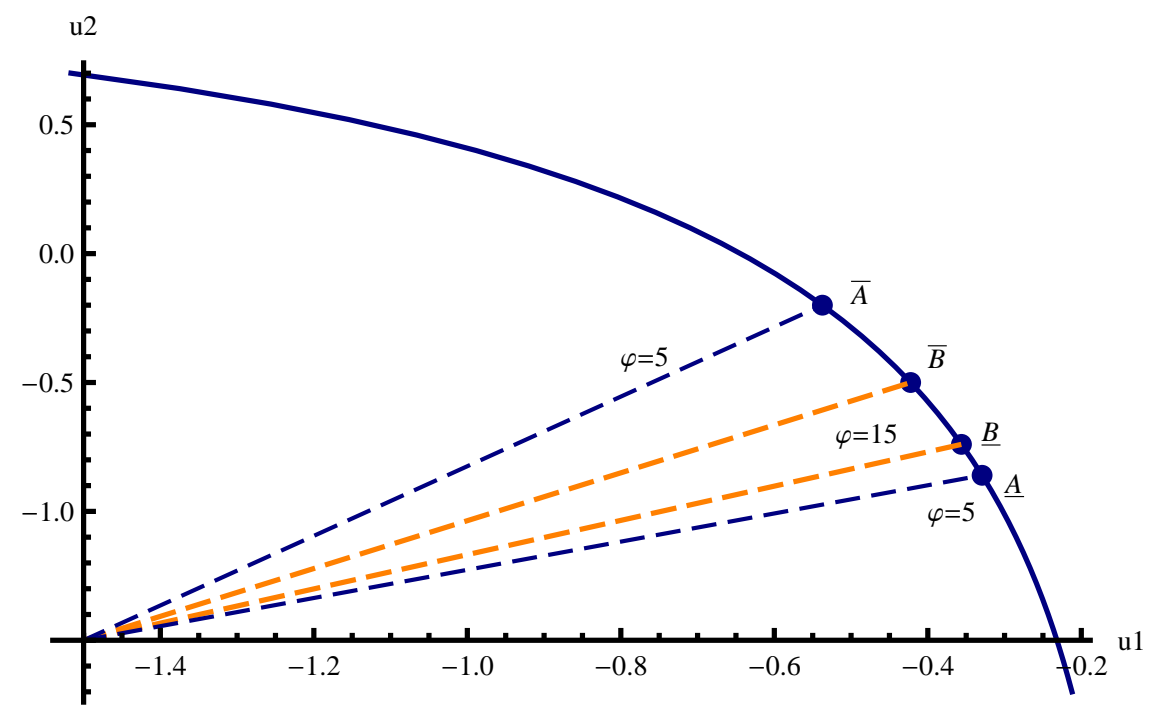

Figure 1. Fairness condition in first-best; $\varphi=5$ vs. $\varphi=15$.

\footnotetext{
${ }^{12}$ In fact, it can be shown that the existence of such a fairness condition is also implied by the presence of pure (instead of genuine) altruism in the utility function.

${ }^{13}$ All figures are based on functional specifications and baseline parameter values that are discussed in Section 5 .
} 
In the next step, we discuss the tax instruments required for the implementation of the first-best allocation characterized by equations (11) - (13). That is, we analyze how the government has to set taxes such that households realize the efficient allocation as a solution to their maximization problem described above. There are two reasons why the government wants to impose taxes. First of all, it wants to redistribute resources since households differ in earning abilities. In addition, redistribution is also implied by the presence of altruism which limits the set of allocations considered as fair. As a personalized lump-sum transfer/tax is available to the government, it can redistribute without distortions. Second, the government wants to correct for the externalities induced by the consumption of the status good. For the sake of simplicity we assume that no tax revenues have to be raised to finance public good expenditures, i.e. taxes are only used to redistribute resources and to internalize the consumption externalities.

When contrasting conditions (11) and (12) with conditions (4) and (5) describing the households' optimality condition, one can see that in general a personalized commodity tax $t_{z, i}$ in addition to the personalized lump-sum element is required to implement the first-best allocation as a competitive equilibrium. ${ }^{14} \mathrm{~A}$ personalized commodity tax is required if the externality is non-atmospheric, because in this case the $\Psi_{i}$ differ between households. If the externality is atmospheric, a uniform tax on status consumption in addition to the lump-sum element suffices to implement a first-best allocation. Commodity $x$ stays untaxed in first best as the externality can be fully internalized with $t_{z, i}$ and redistribution can be achieved through $\tau_{i}$ without distortion. Proposition 1 summarizes this result.

\section{Proposition 1 (First-best tax structure)}

(i) If the externality is atmospheric, then optimal commodity tax rates are given by a single tax on $z, t_{z, i}^{*}=\Psi_{i}=\Psi=t_{z}^{*}$ and $t_{x}^{*}=0$, whether or not the consumption externality is asymmetric.

(ii) If the externality is non-atmospheric, then optimal commodity tax rates are given by differentiated taxes on $z, t_{z, i}^{*}=\Psi_{i}$ and $t_{x}^{*}=0$, whether or not the consumption externality is asymmetric.

(iii) The lump-sum element $\tau_{i}^{*}$ is required for the efficient redistribution of resources.

\footnotetext{
${ }^{14}$ The fact that personalized commodity taxes are required to implement a first-best allocation, when the externalities vary among the individuals causing them, has also been raised by Diamond (1973) and Green and Sheshinski (1976).
} 
Proof. See Appendix.

The intuition for this result is that if the externality is non-atmospheric the status consumption of some households is at the margin socially more harmful than the consumption of other households. This makes it desirable to tax the status consumption of different types at different rates. On the other hand, if the externality is atmospheric the consumption of all households is equally harmful at the margin and a uniform tax rate suffices.

\section{Optimal second-best tax system}

Personalized commodity taxes are required to implement a first-best allocation, but they are hardly a feasible policy instrument. Therefore, we now analyze the secondbest optimal tax policy, when commodity taxes are restricted to be uniform across households. A Pareto efficient second-best tax system is a solution to the following problem:

$$
\max _{t_{x}, t_{z}, \tau_{i}, \bar{z}_{i}, i=1, \ldots, n} v_{1}\left(q_{x}, q_{z}, \tau_{1}, \bar{z}_{1}\right)+\frac{\varphi}{n} \sum_{j=1}^{n} v_{j}\left(q_{x}, q_{z}, \tau_{j}, \bar{z}_{j}\right)
$$

subject to

$$
\begin{array}{ll}
v_{i}\left(q_{x}, q_{z}, \tau_{i}, \bar{z}_{i}\right)+\frac{\varphi}{n} \sum_{j=1}^{n} v_{j}\left(q_{x}, q_{z}, \tau_{j}, \bar{z}_{j}\right) \geq \bar{v}_{i} & i=2, \ldots, n \quad\left(\mu_{i}^{S B}\right) \\
t_{x} \sum_{i=1}^{n} x_{i}+t_{z} \sum_{i=1}^{n} z_{i} \geq \sum_{i=1}^{n} \tau_{i} & \left(\lambda^{S B}\right) \\
\bar{z}_{i}=\frac{1}{n} \sum_{j=1}^{n} a_{i j} z_{j} & i=1, \ldots, n \quad\left(\gamma_{i}^{S B}\right)
\end{array}
$$

where again $\bar{v}_{i}$ is some minimum utility requirement for household $i$. The index SB for the Lagrange multipliers refers to second-best. We provide the first-order conditions for this problem in the Appendix.

\subsection{Optimal commodity taxes}

From the first-order conditions of this maximization problem the optimal commodity tax structure can be derived. To facilitate notation we define

$$
\epsilon_{i} \equiv \frac{1}{n} \sum_{j=1}^{n} \frac{\gamma_{j}^{S B}}{\lambda^{S B}} a_{j i}
$$


It can be interpreted as the marginal social harm induced by the status consumption of household $i$ measured in terms of the government's tax revenues. We assume that $\epsilon_{i}>0$, i.e. that status consumption is socially harmful. ${ }^{15}$

In the Appendix we show that optimal commodity tax rates satisfy

$$
\left(\begin{array}{ll}
\bar{s}_{x x} & \bar{s}_{z x} \\
\bar{s}_{x z} & \bar{s}_{z z}
\end{array}\right)\left(\begin{array}{c}
t_{x} \\
t_{z}
\end{array}\right)=\left(\begin{array}{l}
\frac{1}{n} \sum_{i=1}^{n} \epsilon_{i} s_{z x}^{i} \\
\frac{1}{n} \sum_{i=1}^{n} \epsilon_{i} s_{z z}^{i}
\end{array}\right),
$$

where compensated price effects are denoted by $s_{z k}^{i}=\partial z_{i}^{c o m} / \partial q_{k}$ and $s_{x k}^{i}=\partial x_{i}^{c o m} / \partial q_{k}$, $k=\{z, x\}$, and the upper bar is used to denote the mean. By applying Cramer's rule, (19) yields an implicit solution for the optimal second-best commodity taxes $t_{z}^{* *}$ and $t_{x}^{* *} \cdot 16$

\section{Proposition 2 (Second-best commodity tax structure: general case)}

The optimal second-best commodity taxes are given by

$$
\begin{aligned}
t_{z}^{* *} & =\frac{\frac{1}{n}\left(\bar{s}_{x x} \sum_{i=1}^{n} \epsilon_{i} s_{z z}^{i}-\bar{s}_{x z} \sum_{i=1}^{n} \epsilon_{i} s_{z x}^{i}\right)}{\bar{s}_{z z} \bar{s}_{x x}-\bar{s}_{z x} \bar{s}_{x z}}, \\
t_{x}^{* *} & =\frac{\frac{1}{n}\left(\bar{s}_{z z} \sum_{i=1}^{n} \epsilon_{i} s_{z x}^{i}-\bar{s}_{z x} \sum_{i=1}^{n} \epsilon_{i} s_{z z}^{i}\right)}{\bar{s}_{z z} \bar{s}_{x x}-\bar{s}_{z x} \bar{s}_{x z}} .
\end{aligned}
$$

The optimal tax on the status good is strictly positive. The sign of $t_{x}^{* *}$ is ambiguous.

Proof. See the Appendix.

Observe that both $t_{z}^{* *}$ and $t_{x}^{* *}$ are used to correct for the status externalities as they both depend on the correction element $\epsilon_{i}{ }^{17}$ Thus, the 'additivity property' derived by Sandmo (1975) in a model with an atmospheric externality does not apply. The 'additivity property' states that an externality is best addressed by imposing a tax directly on the externality-generating good and by leaving the rest of the tax system unaffected by the externality. ${ }^{18}$ In our framework it is optimal to also tax good

\footnotetext{
${ }^{15}$ In principle $\gamma_{j}^{S B}$ and by this $\epsilon_{i}$ could also be negative. For a detailed discussion on the sign of the Lagrange multiplier of constraint (17) see Eckerstorfer (2013).

${ }^{16}$ The $2 x 2$ sub-Slutsky matrix of the taxed goods is assumed to be non-singular and negative semi-definite, i.e. a solution to this system of equations exists and the determinant of this matrix is strictly positive.

${ }^{17}$ The optimal tax formulas contain no redistributive component as personalized lump-sum taxes are available. If lump-sum taxes were restricted to be uniform, $t_{z}^{* *}$ and $t_{x}^{* *}$ would also depend on a redistributive term. This can be seen from the many-person Ramsey rule which we provide in the Appendix (equations (64) and (65)).

${ }^{18}$ It has already been shown by Micheletto (2008) and Eckerstorfer (2013) in Mirrlees-type models that this result does not hold if the externality is of the non-atmospheric type, as it is the case in our study. Hence, we confirm this finding for a Ramsey-type optimal tax model.
} 
$x$ to correct for the externality. The intuition for this result can be described in the following way. The government would want to tax the status consumption of different households at different rates. It wants to tax those households at a higher rate whose consumption is socially more harmful at the margin (see Proposition 1). But if commodity tax rates are restricted to be uniform across households such differential treatment of households is not possible. Therefore, the government wants to exploit other possibilities to channel the consumption decision of households in the desired direction, which can be achieved by changing the relative price structure through $t_{z}^{* *}$ and $t_{x}^{* *} \cdot{ }^{19}$

Note that the presence of altruism has no impact on optimal commodity tax rates. This is because the incentive structure of households is not affected by this form of altruism. Households make their decisions independently of the parameter $\varphi$ as they consider average utility in the population as given. Thus, genuine altruism has no impact on the optimality conditions for an efficient allocation. It has, however, distributional consequences and gives rise to a fairness condition which we discuss in subsection 3.3.

To get a better understanding of the optimal commodity tax structure we now consider a number of special cases which provide some insights on how the optimal commodity taxes depend on the specific form of the reference level and on compensated price effects.

\section{Corollary 1 (Second-best commodity tax structure: special cases)}

(i) If the externality is atmospheric and symmetric the optimal commodity tax rates are given by

$$
t_{z}^{* *}=t_{z}^{*}=\epsilon, \quad t_{x}^{* *}=t_{x}^{*}=0,
$$

with $\epsilon \equiv \epsilon_{i}$ for all $i$.

(ii) If the externality is atmospheric and asymmetric optimal commodity tax rates are given by

$$
t_{z}^{* *}=t_{z}^{*}=\epsilon, \quad t_{x}^{* *}=t_{x}^{*}=0,
$$

with $\epsilon \equiv \epsilon_{i}$ for all $i$.

(iii) If $s_{z x}^{i}=0$ or $s_{z x}^{i}=s_{z z}^{i}$ for all $i \in N$ and without any restriction on the reference

\footnotetext{
${ }^{19} \mathrm{~A}$ parallel result is due to Sandmo (1976) who finds that there is a case for a tax or subsidy on related goods in addition to a tax on the externality-generating good when the uses of commodities in particular consumption processes generate externalities (rather than their consumption as such).
} 
levels

$$
t_{z}^{* *}=\frac{\sum_{i=1}^{n} \epsilon_{i} s_{z z}^{i}}{\sum_{i=1}^{n} s_{z z}^{i}}, \quad t_{x}^{* *}=0
$$

(iv) If $s_{z x}^{i}=0$ or $s_{z x}^{i}=s_{z z}^{i}$ for all $i \in N$ and only household $n$ is responsible for the formation of the reference level, such that $a_{i j}=0$ for $j=1, \ldots,(n-1)$ and $a_{i j}=n$ for $j=n$ then

$$
t_{z}^{* *}=\epsilon_{n} \frac{s_{z z}^{n}}{\sum_{i=1}^{n} s_{z z}^{i}}, \quad t_{x}^{* *}=0 .
$$

Optimal commodity taxes in Corollary 1 follow immediately from (20) and (21). Case (i) refers to a scenario where there is a unique reference level (for example the average consumption of the status good) while in case (ii) reference levels differ between households. From cases (i) and (ii) it can be seen that good $x$ needs not to be taxed in the optimum if the externality is of the atmospheric type, no matter whether the externality is asymmetric or not. The optimal tax on the status good is equal to the marginal social harm of status consumption $\epsilon$ if the externality is atmospheric, again no matter whether the externality is asymmetric or not. Note, however, that the expressions for $\epsilon$ differ between cases (i) and (ii) as $\epsilon$ depends on the different values for $a_{i j}$ (see (18)). Thus, whether the externality is symmetric or not has no impact on the optimal commodity tax structure but on the optimal level of $t_{z}^{* *}$. Further, observe that if the externality is atmospheric a uniform tax rate on the status good suffices to fully internalize the externality, and, together with the lump-sum element, a first-best allocation can be reached.

From cases (iii) and (iv) it can be observed that for the optimal commodity tax structure also the structure of compensated price effects is crucial. Given general reference levels, imposing a tax on the nonpositional good is not optimal if compensated cross price effects are zero or if the compensated cross price effects are equal to the own compensated price effect for the status good. ${ }^{20}$ Then households respond in such a way to $t_{x}$ that no additional correction of the externality can be attained. The structure of compensated price effects also has a strong impact on $t_{z}^{* *}$ as can be seen from the reduced tax formulas in (24) and (25). Observe that in cases (iii) and (iv) the externality is non-atmospheric and, thus, the marginal social harm of status consumption $\epsilon_{i}$ differs between households. This implies that the

\footnotetext{
${ }^{20}$ Note that in this case $\bar{s}_{x x}>\bar{s}_{z z}$ which follows from the negative semi-definiteness of the Slutsky matrix and our assumption that it is non-singular.
} 
optimal tax rate on the status good is higher if those households whose consumption is socially more harmful at the margin also have a higher substitution effect due to a price increase of the status good. This can be seen in particular for case (iv) where only the consumption of household $n$ is responsible for the status externality.

\subsection{Optimal lump-sum taxes}

In this subsection we briefly discuss the optimal second-best lump-sum element. As personalized lump-sum taxes or -transfers are available, redistribution can be achieved in a non-distortionary way in this economy. In the optimum the social marginal utility of income is set equal to its marginal cost for all households. This follows immediately from the first-order condition for $\tau_{i}$ from problem (14) $-(17)$ which can be written as

$$
\frac{\theta_{i}^{S B}}{\lambda^{S B}} \frac{\partial v_{i}}{\partial \tau_{i}}=M S C_{i}
$$

with $\theta_{i}^{S B} \equiv \mu_{i}^{S B}+\varphi / n \sum_{j=1}^{n} \mu_{j}^{S B}$ and where the marginal social cost of income $\left(M S C_{i}\right)$ is defined by

$$
M S C_{i} \equiv 1-t_{x} \frac{\partial x_{i}}{\partial \tau_{i}}-t_{z} \frac{\partial z_{i}}{\partial \tau_{i}}+\epsilon_{i} \frac{\partial z_{i}}{\partial \tau_{i}}
$$

The first three terms on the right-hand side of (27) reflect the budget cost of a marginal income increase, and the last term denotes the social harm caused by that income increase due to an increase in status consumption. We now want to find out whether or not in a second-best tax system the lump-sum transfers are also used to correct for the externalities. In first-best, the externalities can be fully internalized by personalized commodity taxes. Then the lump-sum element is not needed for externality correcting purposes and serves only for the redistribution of income. However, in the second-best case the externalities can not be fully internalized due to the restriction that commodity taxes have to be uniform across households. Then one might suspect that also the lump-sum element is required to correct for the externalities. Plugging the optimal commodity taxes given by (20) and (21) into (26) reveals that, in general, a term depending on $\epsilon_{i}$, and therefore on the externality, remains. This implies that the optimal second-best lump-sum element $\tau_{i}^{* *}$ indeed depends on $\epsilon_{i} \cdot{ }^{21}$ The intuition for this result is that $t_{z}^{* *}$ might overcorrect

\footnotetext{
${ }^{21}$ This is not the case if the externality is atmospheric. Then the externalities can be fully internalized with $t_{z}^{* *}$ alone and a first-best allocation can be reached. In this case $M S C_{i}$ is equal to one for all households.
} 
for the status consumption of some households with low $\epsilon_{i}$ and undercorrect for the status consumption of other households with high $\epsilon_{i}$. The lump-sum element can then be used to compensate those whose status consumption causes little social damage (low $\epsilon_{i}$ ) and to extract income from those whose consumption is particularly harmful (high $\epsilon_{i}$ ).

To illustrate this point, consider case (iv) of Corollary 1, where only the status consumption of household $n$ causes an externality. In addition assume that there are no compensated cross price effects. By plugging the expressions for $t_{z}^{* *}$ and $t_{x}^{* *}$ from (25) into (26) one gets

$$
\frac{\theta_{i}^{S B}}{\lambda^{S B}} \frac{\partial v_{i}}{\partial \tau_{i}}=1-\frac{\partial z_{i}}{\partial \tau_{i}} \underbrace{\left(\epsilon_{n} \frac{s_{z z}^{n}}{\sum_{i=1}^{n} s_{z z}^{i}}-\epsilon_{i}\right)}_{\Delta_{i}} .
$$

Observe that $\epsilon_{i}=0$ for all $i=1, \ldots, n-1$ and $\epsilon_{n}>0$. Thus, $\Delta_{i}$ is positive for these households, while $\Delta_{n}$ is negative as $s_{z z}^{n} / \sum_{i=1}^{n} s_{z z}^{i}<1$. This implies $M S C_{i}<1$ for $i=1, \ldots, n-1$ und $M S C_{n}>1$. As marginal utility of income is decreasing in income, the externality has a positive impact on the lump-sum element for those whose consumption does not cause an externality and a negative impact on the lump-sum element for household $n$ who is responsible for the externality. This is in accordance with the intuition provided above, that the lump-sum element is used to compensate those whose consumption is overcorrected by the commodity taxes and to extract income of those households whose consumption is undercorrected. Note that this argument only applies if the externality is non-atmospheric. If the externality is atmospheric it can be fully internalized with $t_{z}$ alone. Then $\Delta_{i}=0$ for all $i$ and the government would set $\tau_{i}$ at its first-best level. Proposition 3 summarizes this result.

\section{Proposition 3 (Second-best lump-sum element)}

(i) If the externality is non-atmospheric then in a second-best tax system also the lump-sum element $\tau_{i}^{* *}$ serves to correct for the externality.

(ii) If the externality is atmospheric then $\tau_{i}^{* *}=\tau_{i}^{*}$ as the externality can be fully internalized through $t_{z}^{* *}=t_{z}^{*}=\epsilon$ alone. 


\subsection{Fairness condition}

We have shown that the presence of altruism has no impact on the optimal commodity tax structure. However, similar to the first-best case, also in second-best a fairness condition exists which limits the set of allocations consistent with the Pareto criterion. There exists a set of allocations which would be Pareto efficient with purely egoistic preferences but which does not satisfy the Pareto criterion if households are altruistic. Intuitively, at such allocations altruistic households would prefer to give income away to those with very little income instead of consuming it on their own. Such a reallocation would make all households better off leading to a Pareto improvement. ${ }^{22}$ Since, in our framework there is no mechanism for households to give money directly to poorer ones, optimal tax policy is affected by the fairness-condition. In second-best, the fairness condition is given by:

$$
\frac{1+\varphi}{\varphi} \geq \frac{1}{n} \sum_{j=1}^{n} \frac{\frac{\partial v_{i} / \partial \tau_{i}}{M S C_{i}}}{\frac{\partial v_{j} / \partial \tau_{j}}{M S C_{j}}}
$$

for all $i=1, \ldots, n$. From (29) it can be seen that in second best the average ratio of marginal utilities of income is weighted by $M S C_{i}$. The fairness condition (29) states that for an allocation to be Pareto efficient the average ratio of the marginal utility of income of household $i$ to that of all other households must not be too large. Interestingly, in the second best case more inequality towards household $i$ is tolerated if the marginal social cost of increasing the income of that household is large. From (27) it can be seen that $M S C_{i}$ increases with the marginal social cost of status consumption of household $i$, as given by $\epsilon_{i}$. That is, if the status consumption of household $i$ is particularly harmful at the margin, then more inequality is tolerated with respect to that household.

In Figure 2 we illustrate this point for two types of households. The figure shows the impact of a consumption externality being non-atmospheric rather than atmospheric on the set of utility allocations that are consistent with the fairness condition in second-best. A shift from an atmospheric to a non-atmospheric externality goes along with a shift in $M S C_{i}$, as in contrast to an atmospheric externality

\footnotetext{
${ }^{22}$ A similar point has been made by Johansson-Stenman (2005) in the context of global environmental problems and the free-riding problem between countries. He shows that if there is a rich and a poor country and the rich country is altruistic toward the poor country, the rich country may still undertake globally efficient abatement investments as it takes utility effects on poor countries into account.
} 
a non-atmospheric externality implies that $\epsilon_{i}$ differs between households. The yellow dashed lines indicate the utility possibility frontier and fair allocations (segment between $\bar{A}$ and $\underline{A}$ ) for the case of an atmospheric consumption externality. The solid blue lines show the respective utility allocations for the non-atmospheric consumption externality with $a_{j 1}>a_{j 2}, j=1,2$, i.e. the consumption of type 1 is socially more harmful at the margin $\left(\epsilon_{1}>\epsilon_{2}\right) .{ }^{23}$

In order to gain intuitive understanding of this result (see Figure 2), we consider the effects of raising $a_{j 1}$ and lowering $a_{j 2}$ - initially starting at $a_{j 1}=a_{j 2}=1$. The slope of the utility possibility frontier is given by the right hand side of (29), with $i=1$. Graphically, the fairness condition, as given by (29), defines upper and lower bounds of the slope of the utility possibility frontier.

The slope of the Pareto frontier increases when raising $a_{j 1}$ and lowering $a_{j 2}$. Intuitively, a given redistribution $\left(d \tau_{1}<0, d \tau_{2}>0\right)$ increases $\tilde{v}_{2}$ by more in case of the non-atmospheric consumption externality as opposed to the atmospheric one. In case of the non-atmospheric consumption externality, the redistribution moves away resources from the main externality generator. As a consequence, $\bar{z}_{i}$ is lowered for all households.

As the slope of the Pareto frontier increases, the set of allocations satisfying the fairness condition shifts up and to the left, as depicted in Figure 2. The fairness condition imposes a requirement on the utility allocation that is very intuitive. As consumer 1 has become the main generator of a negative consumption externality, the fairness condition demands a redistribution of lump sum transfers away from consumer 1 towards consumer 2. In Figure 2, this requirement shows up as a shift of the segment of fair utility allocations towards northeast.

\footnotetext{
${ }^{23}$ Clearly, with the externality being different in the two cases, the utility possibility frontier is different as well.
} 


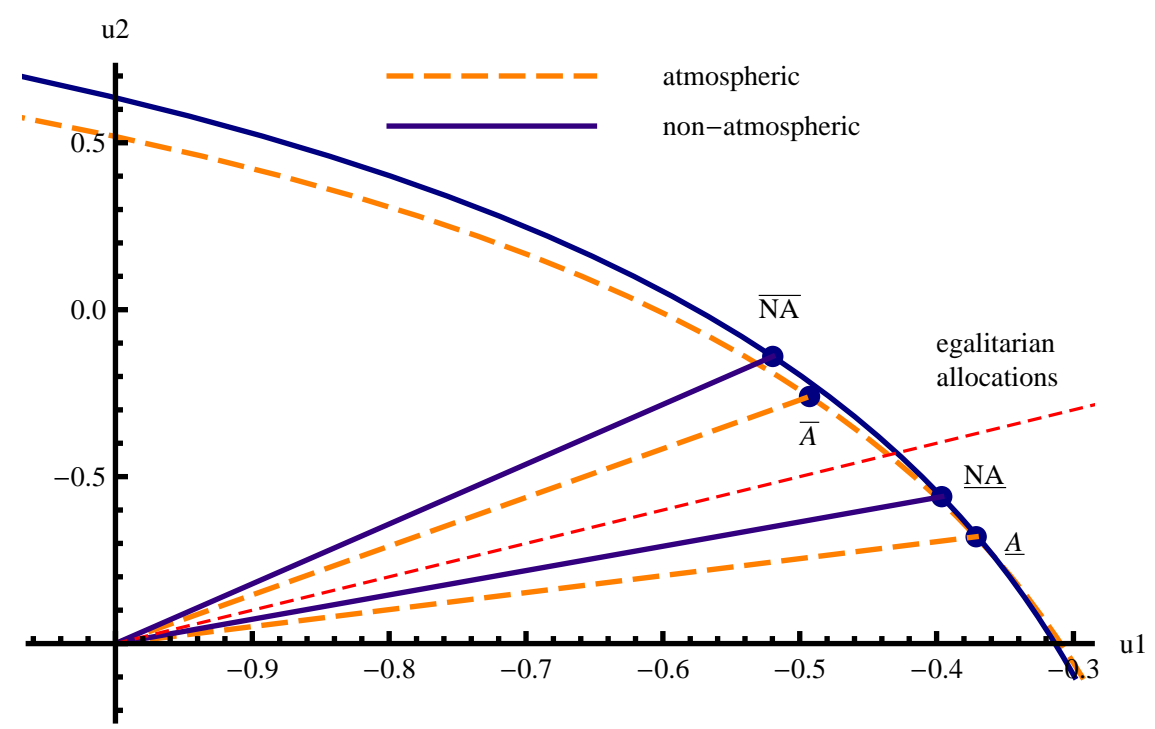

FiguRE 2. Fariness conditions in second-best: atmospheric vs. non-atmospheric externality; $\varphi=5$.

We obtain a similar result if there is a change in the degree in positionality $p_{i}$ (for the functional specification, see Section 5). In Figure 3 we compare the segments of fair utility allocations for two scenarios. In the first scenario indicated by the yellow dashed line both households have the same degree of positionality, while in the second scenario (solid blue line) household 2 is more positional than household 1. One observes that the segment shifts upwards implying that in the second scenario more inequality is tolerated with respect to household 1 and less with respect to the (now) more positional household 2. The key to understand this shift is that in scenario 2 for a marginal rise in lump sum transfers, household 2 gains more utility (from increased z consumption, and from shifting consumption from $x$ to $z$ ) than household 1 due to the higher importance of status consumption for household 2 as compared to household 1. As a consequence (the absolute value) of the slope of the Pareto frontier $v_{1, \tau_{1}} / v_{2, \tau_{2}}$ increases. That is, the investigated changes in $p_{i}$ steepen the Pareto frontier, as can be seen in Figure 3. As the fairness conditions in (29) put constraints on the (minimum- and maximum-) steepness of the Pareto frontier, the steepening of the Pareto frontier - due to changes in $p_{i}$ then implies that the segment consistent with (29) shifts upwards. 


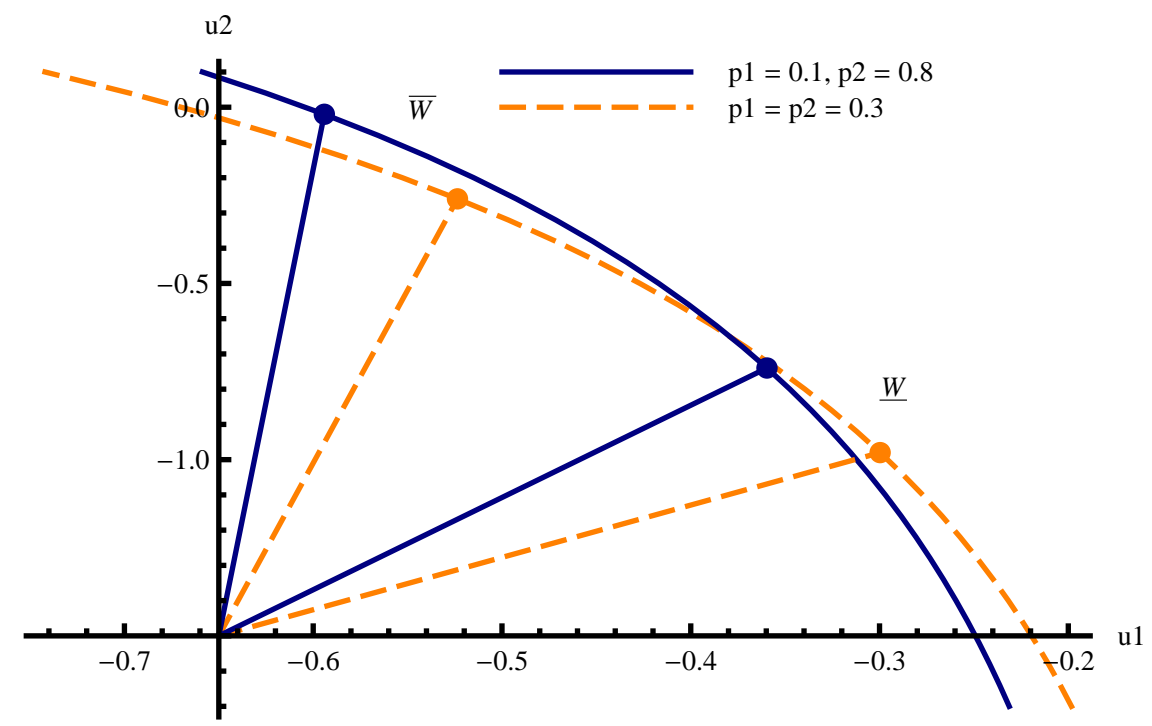

FiguRE 3. Fariness condition in second-best: variation in degree of positionality $p_{i} ; \varphi=5$.

\section{Optimal taxes under a non-welfarist govern- ment}

Should the government accept status effects in its welfare criterion? Concerns for status and relative position are basically a form of jealousy and envy and one can question whether such behavior has to be respected by the policy maker. In this section we analyze the optimal tax policy of a government which knows that households care about status effects but which does not want to include status preferences in the welfare criterion, i.e. the government's and households' preferences differ. So far, the literature has paid almost no attention to the idea that the presence of relative concerns in the social objective might have to be questioned. An exception is Kanbur et al. (2006) who discuss this issue in a survey article on non-welfarist optimal taxation.

We proceed in a similar way as before. First, we characterize the first-best allocation from the perspective of the government and its implementation through taxes, and then in a further step we discuss the optimal second-best tax policy of a non-welfarist government. In order to be able to present the results in a clear way, we assume, from now on, that status preferences enter the utility function 
additively. Preferences of households are described by the concave utility function

$$
\tilde{u}_{i}\left(x_{i}, z_{i}, l_{i}\right)+m_{i}\left(r_{i}\right)+\frac{\varphi}{n} \sum_{j=1}^{n}\left(\tilde{u}_{j}\left(x_{j}, z_{j}, l_{j}\right)+m_{j}\left(r_{j}\right)\right)
$$

where $r_{i} \equiv z_{i} / \bar{z}_{i}$. We assume $m_{r}>0$ and $m_{r r} \leq 0$ for all $i=1, \ldots, n$. The optimal decision of a household is, again, described by conditions (4) and (5) which can also be written as

$$
\begin{gathered}
\frac{\partial \tilde{u}_{i} / \partial z_{i}}{\partial \tilde{u}_{i} / \partial x_{i}}+\underbrace{\frac{1}{\bar{z}_{i}} \frac{\partial m_{i} / \partial r_{i}}{\partial \tilde{u}_{i} / \partial x_{i}}}_{\tilde{\Psi}_{i}}=\frac{1+t_{z}}{1+t_{x}} \\
\frac{\partial \tilde{u}_{i} / \partial l_{i}}{\partial \tilde{u}_{i} / \partial x_{i}}=\frac{w_{i}}{1+t_{x}}
\end{gathered}
$$

We call $\tilde{\Psi}_{i}$ the part of the $M R S_{z x}^{i}$ that stems from relative consumption concerns, that is it tells how much of good $x$ a household is willing to give up for the better relative position an additional unit of $z$ provides. Note that in general $\tilde{\Psi}_{i}$ differs between households.

The government knows that households base their decisions on the utility function in (30) but it behaves in a paternalistic way and ignores $m_{i}\left(r_{i}\right)$ in its welfare criterion. Let the indirect utility function of a household be given by

$$
\underbrace{\tilde{u}_{i}\left(z_{i}^{*}(\cdot), x_{i}^{*}(\cdot), l_{i}^{*}(\cdot)\right)}_{\tilde{v}_{i}\left(q_{x}, q_{z}, \tau_{i}, \bar{z}_{i}\right)}+\underbrace{m_{i}\left(\frac{z_{i}^{*}(\cdot)}{\bar{z}_{i}}\right)}_{s_{i}\left(q_{x}, q_{z}, \tau_{i}, \bar{z}_{i}\right)}+\frac{\varphi}{n} \sum_{j=1}^{n}(\underbrace{\tilde{u}_{j}\left(z_{j}^{*}(\cdot), x_{j}^{*}(\cdot), l_{j}^{*}(\cdot)\right)}_{\tilde{v}_{j}\left(q_{x}, q_{z}, \tau_{j}, \bar{z}_{j}\right)}+\underbrace{m_{j}\left(\frac{z_{j}^{*}(\cdot)}{\bar{z}_{j}}\right)}_{s_{j}\left(q_{x}, q_{z}, \tau_{j}, \bar{z}_{j}\right)}) .
$$

The government considers only $\tilde{v}_{i}+\frac{\varphi}{n} \sum_{j=1}^{n} \tilde{v}_{j}$ in the welfare criterion. Hence, the altruistic part of individual utility is included in the welfare criterion while the utility part $s_{i}$ emerging from the relative position of households will be omitted. ${ }^{24}$

\subsection{Characterization of first-best allocations}

We first characterize first-best allocations from the perspective of the government. Assume again that the government can directly determine $x_{i}, z_{i}, l_{i}$ for each household $i$. Then an efficient first-best allocation from the perspective of the government

\footnotetext{
${ }^{24}$ One implication of this is that the envelope theorem has to be used with care when taking derivatives of $\tilde{v}_{i}$. For example Roy's identity becomes $\frac{\partial \tilde{v}_{i}}{\partial t_{z}}=-z_{i} \frac{\partial \tilde{v}_{i}}{\partial \tau_{i}}-\left(\frac{\partial s_{i}}{\partial t_{z}}+z_{i} \frac{\partial s_{i}}{\partial \tau_{i}}\right)$.
} 
is a solution to the problem

$$
\max _{x_{i}, z_{i}, l_{i}, i=1, \ldots, n} \tilde{u}_{1}\left(x_{1}, z_{1}, l_{1}\right)+\frac{\varphi}{n} \sum_{j=1}^{n} \tilde{u}_{j}\left(x_{j}, z_{j}, l_{j}\right)
$$

subject to

$$
\begin{aligned}
& \tilde{u}_{i}\left(x_{i}, z_{i}, l_{i}\right)+\frac{\varphi}{n} \sum_{j=1}^{n} \tilde{u}_{j}\left(x_{j}, z_{j}, l_{j}\right) \geq \bar{u}_{i} \quad i=2, \ldots, n \quad\left(\tilde{\mu}_{i}^{F B}\right) \\
& \sum_{i=1}^{n} x_{i}+\sum_{i=1}^{n} z_{i}=\sum_{i=1}^{n} w_{i}\left(1-l_{i}\right)
\end{aligned}
$$

Observe that the government ignores the reference consumption levels and their impact on private utility in its maximization problem. In the Appendix, we provide the first-order conditions for this problem from which the following optimality conditions can be derived:

$$
\begin{gathered}
\frac{\partial \tilde{u}_{i} / \partial z_{i}}{\partial \tilde{u}_{i} / \partial x_{i}}=1, \\
\frac{\partial \tilde{u}_{i} / \partial l_{i}}{\partial \tilde{u}_{i} / \partial x_{i}}=w_{i}, \\
\frac{1+\varphi}{\varphi} \geq \frac{1}{n} \sum_{j=1}^{n} \frac{\partial \tilde{u}_{i} / \partial x_{i}}{\partial \tilde{u}_{j} / \partial x_{j}},
\end{gathered}
$$

for all $i=1, \ldots, n$. From (38) and (39) it can be seen that if households had no relative consumption concerns, the government would not want to distort their consumption and leisure decision. But since households care about status consumption, the government wants to distort the decision of households so that they behave as if they had no status concerns. In other words, the government wants to correct for the status preferences. In addition, similar to the welfarist case, the fairness condition given by (40) limits the set of allocations consistent with the Pareto criterion. This fairness condition also holds in the non-welfarist case because the government respects altruism to be part of the welfare criterion. ${ }^{25}$

In order to see which tax instruments are required to implement a first-best allocation, one has to contrast conditions (38) and (39) with the optimality conditions

\footnotetext{
${ }^{25}$ In the next section, for a specified utility function, we compare the fairness condition of a welfarist with that of a non-welfarist government. There we show that the set of allocations considered as fair by a non-welfarist government is a strict subset of the set of allocations considered as fair by a welfarist government.
} 
of a household given by (31) and (32). Similar to the welfarist case, a personalized commodity tax $\tilde{t}_{z, i}^{*}=\tilde{\Psi}_{i}$ on the status good, in addition to the personalized lump-sum element, is required to implement a first-best allocation as a competitive equilibrium. Only if $\tilde{\Psi}_{i}$ is constant across households, a uniform commodity tax on all households would suffice. In contrast to the welfarist case, whether or not a uniform tax on the status good suffices to implement the first-best allocation does not depend on whether the externality is atmospheric or not. A uniform tax rate on the status good suffices if the externality is symmetric - which implies that $\bar{z}_{i}=\bar{z}$ - and if $m_{r} / \tilde{u}_{x}$ is constant across households. A personalized commodity tax is required in the non-welfarist case if different households are willing to give up different amounts of $x$ for the better relative position an additional unit of $z$ provides. This is the case if $\tilde{\Psi}_{i}$ differs across households. Note that the nature of the externality does not affect the first-best tax rate if $\partial M R S_{z x} / \partial \bar{z}_{i}=0$, as then the household decision does not depend on $\bar{z}_{i}$. Proposition 4 summarizes this result.

\section{Proposition 4 (Non-welfarist government: first-best tax structure)}

(i) In general optimal commodity tax rates are given by differentiated taxes on $z$, $\tilde{t}_{z, i}^{*}=\tilde{\Psi}_{i}$ and $\tilde{t}_{x}^{*}=0$, whether or not the consumption externality is non-atmospheric. (ii) If the externality is atmospheric and symmetric and if $m_{r} / \tilde{u}_{x}$ is the same for all households, then optimal commodity tax rates are given by a single tax on $z$, $\tilde{t}_{z, i}^{*}=\tilde{\Psi}_{i}=\tilde{\Psi}=\tilde{t}_{z}^{*}$ and $\tilde{t}_{x}^{*}=0$.

(iii) The nature of the consumption externality has no impact on $\tilde{t}_{z}^{*}$ and $\tilde{t}_{x}^{*}$ if $\partial M R S_{z x} / \partial \bar{z}_{i}=0$.

(iv) The lump-sum element $\tilde{\tau}_{i}^{*}$ is required for the efficient redistribution of resources. Proof. See Appendix.

Loosely speaking some households care more about status than others, hence a government which wants to correct for status preferences would want to treat these households differently. In contrast to the previous section it is not important how different households contribute to the reference level. Now the crucial aspect is that some households are willing to give up more for additional status than others. 


\subsection{Optimal second-best tax system}

If personalized commodity taxes are not feasible, a second-best tax system, from the perspective of the government, is a solution to the following problem:

$$
\max _{t_{x}, t_{z}, \tau_{i}, \bar{z}_{i}, i=1, \ldots, n} \tilde{v}_{1}\left(q_{x}, q_{z}, \tau_{1}, \bar{z}_{1}\right)+\frac{\varphi}{n} \sum_{j=1}^{n} \tilde{v}_{j}\left(q_{x}, q_{z}, \tau_{j}, \bar{z}_{j}\right)
$$

subject to

$$
\begin{array}{lcc}
\tilde{v}_{i}\left(q_{x}, q_{z}, \tau_{i}, \bar{z}_{i}\right)+\frac{\varphi}{n} \sum_{j=1}^{n} \tilde{v}_{j}\left(q_{x}, q_{z}, \tau_{j}, \bar{z}_{j}\right) \geq \bar{v}_{i} & i=2, \ldots, n & \left(\tilde{\mu}_{i}^{s B}\right) \\
t_{x} \sum_{i=1}^{n} x_{i}+t_{z} \sum_{i=1}^{n} z_{i} \geq \sum_{i=1}^{n} \tau_{i} & \left(\tilde{\lambda}^{S B}\right) \\
\bar{z}_{i}=\frac{1}{n} \sum_{j=1}^{n} a_{i j} z_{j} & i=1, \ldots, n & \left(\tilde{\gamma}_{i}^{S B}\right)
\end{array}
$$

The first-order conditions for this problem are provided in the Appendix. Note that the only difference to problem $(14)-(17)$ is the objective function in which the status part of the utility function is now omitted. Still, $\tilde{v}_{i}$ is affected by the reference level through the effect of $\bar{z}_{i}$ on $x, z, l{ }^{26}$ Thus, when designing the optimal tax system the effect of taxes on the reference levels has to be taken into account, even though the direct impact of $\bar{z}_{i}$ on individual utility is not considered.

From the first-order conditions of problem (41) - (44) one can derive an implicit solution for the optimal second-best commodity taxes chosen by a non-welfarist government.

\section{Proposition 5 (Non-welfarist government: second-best commodity taxes)}

The optimal second-best commodity taxes from the perspective of a non-welfarist government are given by

$$
\begin{aligned}
& \tilde{t}_{z}^{* *}= \frac{\frac{1}{n}\left(\bar{s}_{x x} \sum_{i=1}^{n} \frac{\tilde{\theta}_{i}^{S B}}{\tilde{\lambda}^{S B}} \frac{1}{\bar{z}_{i}} \frac{\partial m}{\partial r_{i}} s_{z z}^{i}-\bar{s}_{x z} \sum_{i=1}^{n} \frac{\tilde{\theta}_{i}^{S B}}{\tilde{\lambda}^{S B}} \frac{1}{\bar{z}_{i}} \frac{\partial m}{\partial r_{i}} s_{z x}^{i}\right)}{\bar{s}_{z z} \bar{s}_{x x}-\bar{s}_{z x} \bar{s}_{x z}} \\
&+\frac{\frac{1}{n}\left(\bar{s}_{x x} \sum_{i=1}^{n} \tilde{\epsilon}_{i} s_{z z}^{i}-\bar{s}_{x z} \sum_{i=1}^{n} \tilde{\epsilon}_{i} s_{z x}^{i}\right)}{\bar{s}_{z z} \bar{s}_{x x}-\bar{s}_{z x} \bar{s}_{x z}}
\end{aligned}
$$

\footnotetext{
${ }^{26}$ The sign of $\tilde{v}_{\bar{z}}$ is ambiguous. In contrast to the previous section, now the government only takes the indirect effect of $\bar{z}_{i}$ on $\tilde{u}_{i}(x, z, l)$ through its effect on demand for $x, z, l$ into account and not the direct impact on $m_{i}\left(r_{i}\right)$.
} 


$$
\begin{aligned}
\tilde{t}_{x}^{* *}= & \frac{\frac{1}{n}\left(\bar{s}_{z z} \sum_{i=1}^{n} \frac{\tilde{\theta}_{i}^{S B}}{\tilde{\lambda}^{S B}} \frac{1}{z_{i}} \frac{\partial m}{\partial r_{i}} s_{z x}^{i}-\bar{s}_{z x} \sum_{i=1}^{n} \frac{\tilde{\theta}_{\tilde{\lambda}}^{S B}}{\bar{s}^{S B}} \frac{1}{\bar{z}_{i}} \frac{\partial m}{\partial r_{i}} s_{z z}^{i}\right)}{\bar{s}_{z z} \bar{s}_{x x}-\bar{s}_{z x} \bar{s}_{x z}} \\
+ & \frac{\frac{1}{n}\left(\bar{s}_{z z} \sum_{i=1}^{n} \tilde{\epsilon}_{i} s_{z x}^{i}-\bar{s}_{z x} \sum_{i=1}^{n} \tilde{\epsilon}_{i} s_{z z}^{i}\right)}{\bar{s}_{z z} \bar{s}_{x x}-\bar{s}_{z x} \bar{s}_{x z}}
\end{aligned}
$$

where $\tilde{\theta}_{i}^{S B} \equiv \tilde{\mu}_{i}^{S B}+\varphi / n \sum_{j=1}^{n} \tilde{\mu}_{j}^{S B}$ and $\tilde{\epsilon}_{i} \equiv n^{-1} \sum_{j=1}^{n}\left(\tilde{\gamma}_{j}^{S B} / \tilde{\lambda}^{S B}\right) a_{j i}$.

Proof. See Appendix.

The optimal commodity tax rates depend on two terms now. The first term can be interpreted as the preference correcting part of the optimal tax formulas. From the perspective of the government households consume too much of the status good and it wants to deter individuals to purchase good $z$ just for status reasons. Therefore, this term is strictly positive in the case of $\tilde{t}_{z}^{* *}$, making the status good more expensive. Note that $\tilde{t}_{x}^{* *}$ also depends on a preference correcting part, given by the first term on the right-hand side (46). The reason is similar to the welfarist case in which $t_{x}$ is used to correct for the status externality. Due to differences across households in their willingness to pay for additional status the government would want to tax status consumption of each household at a different rate. Since it is restricted to use a single rate, it is optimal to use other tax instruments to correct for status preferences. The sign of the correction term in the case of $\tilde{t}_{x}^{* *}$ is ambiguous.

The second term on the right hand side of (45) and (46) looks very similar to the term determining the optimal commodity tax rates in the welfarist case. However, its interpretation is different as $\tilde{\epsilon}_{i}$ differs from $\epsilon_{i}$. If the government has a welfarist objective function, $\epsilon_{i}$ basically describes the marginal welfare cost of an increase in the externality level $\bar{z}_{i}$. In the case of a non-welfarist government there is no direct welfare loss associated with an increase of $\bar{z}_{i}$. But since demand for $x, z, l$ reacts to changes in the reference levels there is an indirect effect of $\bar{z}_{i}$ on the objective function and on commodity tax revenues and these effects are summarized by $\tilde{\epsilon}_{i}$. Thus, when determining $\tilde{t}_{z}^{* *}$ and $\tilde{t}_{x}^{* *}$ the government has to take the effect of taxes on the reference levels into account, even though it has no externality-correcting motive.

Similarly to the welfarist case the optimal commodity tax structure depends crucially on compensated price effects and on how the reference levels are formed. 
Corollary 2 (Non-welfarist government: second-best commodity tax structure - special cases)

(i) If the externality is atmospheric and symmetric and if $\frac{\tilde{\theta}_{i}^{S B}}{\tilde{\lambda}^{S B}} \frac{\partial m_{i}}{\partial r_{i}}=\frac{\tilde{\theta}_{\hat{\lambda}}^{S B}}{\tilde{\lambda}^{S B}} \frac{\partial m}{\partial r}$ for all $i \in N$, optimal commodity tax rates are given by

$$
\tilde{t}_{z}^{* *}=\tilde{t}_{z}^{*}=\frac{\tilde{\theta}^{S B}}{\tilde{\lambda}^{S B}} \frac{1}{\bar{z}} \frac{\partial m}{\partial r}, \quad \tilde{t}_{x}^{* *}=\tilde{t}_{x}^{*}=0 .
$$

(ii) If $s_{z x}^{i}=0$ or $s_{z x}^{i}=s_{z z}^{i}$ for all $i \in N$ and without any restriction on the reference levels

$$
\tilde{t}_{z}^{* *}=\frac{1}{\sum_{i=1}^{n} s_{z z}^{i}}\left(\sum_{i=1}^{n} \frac{\tilde{\theta}_{i}^{S B}}{\lambda \tilde{S} B} \frac{1}{\bar{z}_{i}} \frac{\partial m}{\partial r_{i}} s_{z z}^{i}+\sum_{i=1}^{n} \tilde{\epsilon}_{i} s_{z z}^{i}\right), \quad \tilde{t}_{x}^{* *}=0 .
$$

Proof. See Appendix.

Case (i) refers to a scenario in which there is a unique reference level and in which the consumption of all households is weighted equally in the formation of that reference level. If in addition $\frac{\tilde{\theta}_{i}^{S B}}{\tilde{\lambda}^{S B}} \frac{\partial m_{i}}{\partial r_{i}}$ is the same for all households then the firstbest allocation can be implemented without personalized commodity taxes and good $x$ needs not to be taxed. This statement is equivalent to the one in Proposition 4 (ii). Observe that for a welfarist government a uniform tax on the status good in addition to the lump-sum element suffices to implement the first-best allocation as soon as the externality is atmospheric (see Corollary 1). For a non-welfarist government more conditions are required. This is because a non-welfarist government has to take two aspects into account when correcting for status consumption, namely correction of preferences and correction of the indirect effect of the reference level on social welfare. For the former the heterogeneity in preferences among households for status consumption matters, for the latter the heterogeneity among households in the generation of the reference levels matters.

From case (ii) it can be seen that also in the non-welfarist case the structure of compensated price effects has a strong impact on optimal commodity taxes. If there are no compensated cross price effects or if the compensated cross price effects are equal to the own compensated price effect for the status good, then good $x$ needs not to be taxed to correct for status preferences and the optimal tax formula on the status good simplifies substantially (see equation (48)) 
With respect to the optimal-lump sum element, a similar result to the one provided in the welfarist case can be derived. By plugging optimal commodity taxes into the first-order condition for $\tilde{\tau}_{i}$, it can be seen that $\tilde{\tau}_{i}^{* *}$ also serves to correct for status preference if a uniform tax on the status good does not suffice to fully correct for status preferences. Loosely speaking, the lump-sum element can be used to compensate those who have no or only a very weak taste for status and whose consumption of good $z$ is overcorrected by the commodity taxes. From those who have a very strong taste for status, additional correction of status consumption can be achieved by extracting income through the lump-sum element.

Also in second-best a non-welfarist government has to take a fairness condition into account which limits the set of allocations consistent with the Pareto criterion. The reason is that the government respects altruism to be part of the utility function. Formally the fairness condition is now given by

$$
\frac{1+\varphi}{\varphi} \geq \frac{1}{n} \sum_{j=1}^{n} \frac{\frac{\partial \tilde{v}_{i} / \partial \tilde{\tau}_{i}}{\overline{M S C_{i}}}}{\frac{\partial \tilde{v}_{j} / \partial \tilde{\tau}_{j}}{\overline{M S C_{j}}}}
$$

for all $i=1, \ldots, n .^{27}$ Thus, again for an allocation to be Pareto effcient the weighted average ratio of the marginal utility of income between household $i$ and all other households must not be too large.

Interestingly, the structure of an optimal tax system of a welfarist government looks similar to that of a non-welfarist government. However, taxes are used for different reasons in the two scenarios. In the case of a welfarist government, the main objective is to correct for the status externalities, while a non-welfarist government wants to correct for the status preferences of individuals. In order to be able to make comparisons with respect to the magnitude of optimal commodity taxes in the two scenarios and to study the quantitative impact of the reference levels on optimal taxes we conduct some numerical simulations, which we present in the next section.

\footnotetext{
${ }^{27}$ In the non-welfarist case we define the marginal social cost of increasing income for household $i$ by $\widetilde{M S C}_{i} \equiv 1-t_{x} \frac{\partial x_{i}}{\partial \tau}{ }_{i}-t_{z} \frac{\partial z_{i}}{\partial \tau_{i}}+\tilde{\epsilon}_{i} \frac{\partial z_{i}}{\partial \tau} i_{i}$. For a derivation of (49), we proceed in the same way as in the derivation of the fairness condition for the welfarist case (see Appendix).
} 


\section{Results from Numerical Simulations}

The above propositions imply the qualitative result that the nature of the consumption externality does have an impact on the first-best and second-best efficient commodity tax rates both for a welfarist and for a non-welfarist welfare criterion. Considering reasonable calibrations, three main quantitative questions suggest themselves. First, for a given consumption externality (benchmark case), how different are first-best and second-best efficient commodity tax rates between the welfarist and the non-welfarist case? Second, what are the effects of the nature of the consumption externality - whether it is atmospheric or non-atmospheric, whether it is symmetric or asymmetric - on the first-best and second-best commodity tax rate of the positional good both in the welfarist and the non-welfarist case? Third, in a second-best setting, what is the impact of the nature of the consumption externality on the commodity tax rate of the non-positional good, which is essentially zero in the first-best?

Numerical simulations, addressing these questions, are presented in the following. The results of those simulations are not intended to suggest precise first-best or second-best tax rates on (non-)positional goods. Rather, they are intended to provide a rough indication of how important the nature of the consumption externality for efficient tax rates - under a reasonable calibration - is. Therefore, the numerical simulations focus on the change of efficient tax rates due to the consumption externality rather than on the levels of efficient tax rates.

We employ a simple specified model with two types of households, 1 and 2 . There are $n$ households. A share of $\eta$ is of type 1 , and a share of $(1-\eta)$ is of type 2. Household types differ with respect to three attributes: preferences, labor productivity, and (possibly) externality coefficients $a_{i j}$. Every household is endowed with one unit of time. A household of type $i$ receives a wage rate of $w_{i}$ per unit of labor supplied. Preferences are represented by the following utility functions.

$$
u_{i}\left(x_{i}, z_{i}, l_{i}, \bar{z}_{i}\right)=\alpha_{i} \ln x_{i}+\beta_{i} \ln \left[z_{i}\left(\frac{z_{i}}{\bar{z}_{i}}\right)^{p_{i}}\right]+\gamma_{i} \ln l_{i}, \quad i=1,2,
$$

where $\bar{z}_{i} \equiv \eta a_{i 1} z_{1}+\eta a_{i 2} z_{2}$. Notice that these utility functions satisfy the separability requirement of the non-welfarist case. Preference parameter $p_{i}$ represents the strength of "positionality." If $p_{i}=0$, the consumption reference level does not affect type $i$ 's behavior. However, the higher is $p_{i}$, the stronger is the impact of $\bar{z}_{i}$ on 
household type $i$ 's behavior. Johansson-Stenman et al. (2002) refer to $\left[p_{i} /\left(1+p_{i}\right)\right]$ as the marginal degree of positionality.

What we call baseline values of the background parameters is listed in Table 1. Unless stated otherwise, tables and graphs are based on these parameter values that imply standard stylized facts, as discussed below.

\section{TABLE 1}

\begin{tabular}{lrrr} 
BASELINE VALUES OF & \multicolumn{3}{c}{ BACKGROUND PARAMETERS } \\
\hline \multirow{2}{*}{ Households } & & Type 1 & Type 2 ("rich") \\
Preference parameters & $\alpha_{i}$ & $1 / 3$ & $1 / 4$ \\
& $\beta_{i}$ & $5 / 12$ & $5 / 12$ \\
& $\gamma_{i}$ & $1 / 4$ & $1 / 3$ \\
& $p_{i}$ & $1 / 5$ & $2 / 5$ \\
Productivity & $w_{i}$ & 2 & 4 \\
Externality parameters & $a_{1 i}$ & $4 / 5$ & $9 / 5$ \\
& $a_{2 i}$ & $3 / 5$ & $13 / 5$ \\
Share parameter & $\eta_{i}$ & $4 / 5$ & $1 / 5$ \\
Utility & $u_{i}$ & endogenous & $-7 / 20$ \\
\hline
\end{tabular}

Note. Notice that $\eta_{1} a_{i 1}+\eta_{2} a_{i 2}=1$.

With this parameterization, households of type 2 are considered significantly wealthier than households of type $1\left(w_{2}>w_{1}\right)$. Consistent with empirical evidence, those households have a stronger impact on the consumption reference levels than type 1-households $\left(a_{i 2}>a_{i 1}\right)$. Roughly, households of type 2 are rich and they are the primary externality generators. These households are typically a small group within an economy. Therefore, we give this group just a small weight $((1-\eta)=1 / 5)$.

Regarding the degree of positionality, we consider "rich" households as at least as positional as other households. Specifically, $2 / 5=p_{2}>p_{1}=1 / 5$. Empirical studies, including Alvarez-Cuadrado et al. (2012), Maurer et al. (2008), Ravina (2007), or Wendner and Goulder (2008) demonstrate that the marginal degree of positionality falls into the range $[0.2,0.4]$. Converting this range into a range for our $p_{i}$ yields $p_{i} \in[0.25,0.67]$. In our study we are quite conservative and consider the low end of $p_{i}=0.2$, and the high end of $p_{i}=0.4$ (see Table 1).

Minimum utility of household type 2 is chosen to amount to a value of -0.35 . As $w_{2}>w_{1}$, this value is somewhat higher than the endogenous value of $u_{1}$. Given this 
parameterization, we fix the values of the other preference parameters $\left(\alpha_{i}, \beta_{i}, \gamma_{i}\right)$ so that households choose an employment share in between $(0.6,0.75)$, that is, $l_{i} \in(0.25,0.4)$. Close to no empirical evidence exists for the coefficients $a_{i j}$. Therefore, most numerical simulations deal with the sensitivity of efficient tax rates with respect to $a_{i j}$. We are now ready to turn to our first question.

\subsection{Welfarist versus non-welfarist tax rates}

For the consumption externality as given by the baseline values (Table 1), how different are first-best and second-best efficient commodity tax rates between the welfarist and the non-welfarist case?

\section{TABLE 2}

\section{Welfarist versus Non-WELFARist TAX RATES (BASEline VAlues)}

\begin{tabular}{lrrrr}
\hline & FB welfarist & SB welfarist & FB non-welfarist & SB non-welfarist \\
$t_{z, 1}, t_{z, 2}$ & $0.17,0.50$ & 0.26 & $0.20,0.40$ & 0.26 \\
$t_{x}$ & 0.000 & 0.014 & 0.000 & 0.007 \\
$\tau_{1}, \tau_{2}$ & $0.35,-0.14$ & $0.45,-0.44$ & $0.36,-0.17$ & $0.41,-0.33$ \\
$u_{1}$ & -0.47 & -0.48 & -0.47 & -0.47 \\
$x_{1}, x_{2}$ & $0.72,0.83$ & $0.74,0.75$ & $0.73,0.82$ & $0.74,0.78$ \\
$z_{1}, z_{2}$ & $0.93,1.28$ & $0.90,1.41$ & $0.91,1.37$ & $0.88,1.46$ \\
$\bar{z}_{1}, \bar{z}_{2}$ & $1.06,1.11$ & $1.08,1.17$ & $1.07,1.15$ & $1.09,1.18$ \\
$l_{1}, l_{2}$ & $0.27,0.28$ & $0.28,0.25$ & $0.27,0.27$ & $0.28,0.26$ \\
\hline
\end{tabular}

Note. $\mathrm{FB}=$ first-best, $\mathrm{SB}=$ second-best. In $\mathrm{SB}$, a unique value for $t_{z}$ is given, as $t_{z 1}=t_{z 2}$.

Table 2 suggests three main results. First, in the first-best, the efficient tax rate on the positional good is vastly sensitive with respect to a household's strength of externality generation. For the baseline calibration, household type 2 is the primary generator of the consumption externality $\left(a_{i 2}>a_{i 1}, i=1,2\right)$. In the welfarist (nonwelfarist) case, $t_{z, 2}$ is three times (twice) as large as $t_{z, 1}$. Second, in the second-best, the efficient tax on the non-positional good is different from zero, but quite small as compared to $t_{z}$. In the welfarist (non-welfarist) case, $t_{x}=1.4 \%\left(t_{x}=0.7 \%\right.$ ). That is, from a corrective point of view, positional and non-positional commodities need to be taxed highly differently. Third, the above observations hold for both the welfarist and the non-welfarist case. In the latter, however, (most) commodity tax rates are significantly smaller than in the former. Intuitively, a non-welfarist government — by not taking into account the positionality term, $m_{i}\left(r_{i}\right)$, in its 
welfare criterion - does not need to correct for the direct effect of the consumption externality on welfare. In the first-best, therefore, the tax rates on the positional good tend to be lower and less different from each other than in the welfarist case. The less different the $t_{z, i}$ are in the first-best, the better a uniform $t_{z}$ in second-best is able to mimic the first-best tax regime, thus, the lower is $t_{x}$ in the second-best. As seen in Table 2, in the non-welfarist case the tax rate $t_{x}$ comes down to only half the value it amounts to in the welfarist case.

\subsection{Welfarist versus non-welfarist tax rates and the nature of the consumption externality}

This subsection considers the effects of the nature of the consumption externality on the first-best and second-best commodity tax rates of the positional good both in the welfarist and the non-welfarist case.

\subsubsection{Efficient taxation in the first-best}

In Table 3 below, by systematically varying coefficients $a_{i j}$, we identify the effects on efficient commodity tax rates of the consumption externality being non-atmospheric rather than atmospheric as well as being asymmetric rather than symmetric. Specifically, Panel A considers an atmospheric and symmetric consumption externality $\left(a_{i j}=1\right)$. Panel B takes up a non-atmospheric and symmetric consumption externality. Comparing Panels A and B allows some inference of the impact of the consumption externality being non-atmospheric rather than atmospheric on efficient taxation. Panels C.1 and C.2 investigate a non-atmospheric and asymmetric consumption externality. Comparing Panels B and C allows some assessment of the effects of the consumption externality being asymmetric rather than symmetric.

Table 3 offers several insights. Here we focus on the first-best tax regimes, for which $t_{x}=0$. In the following subsection, we focus on the second-best tax regimes. In order to sharpen the differences between the welfarist and the non-welfarist case, preferences (50) are chosen such that only direct effects - effects via the welfare criterion - are caused by $\bar{z}_{i}{ }^{28}$

\footnotetext{
28 In other words, in the optimum, $\left(x_{i}, z_{i}, l_{i}\right)$ are affected by $p_{i}$ but not by $\bar{z}_{i}$. Thus, in the non-welfarist case, individual behavior is independent of the composition of $\bar{z}_{i}$. As the welfare criterion is independent of $\bar{z}_{i}$ too, the efficient non-welfarist tax regimes are identical across Panels A to C.2. In contrast, in the welfarist case, the welfare criterion does depend on $\bar{z}_{i}$. Thus, the efficient welfarist tax regime also depends on the composition of $\bar{z}_{i}$.
} 
To begin with, consider the first column, labeled "FB welfarist", of Table 3 . It is evident that the nature of the consumption externality does have a major impact on the first-best efficient tax rates of the positional good. In particular - in the welfarist case $-t_{z, i}$ is identical across individuals as long as the consumption externality is atmospheric. Once it becomes non-atmospheric, $t_{z, i}$ vary greatly across household types, no matter whether the externality is asymmetric or not, as seen from comparing Panel A with Panels B , C.1, and C.2.

TABLE 3

Effects of the Nature of the Consumption Externality

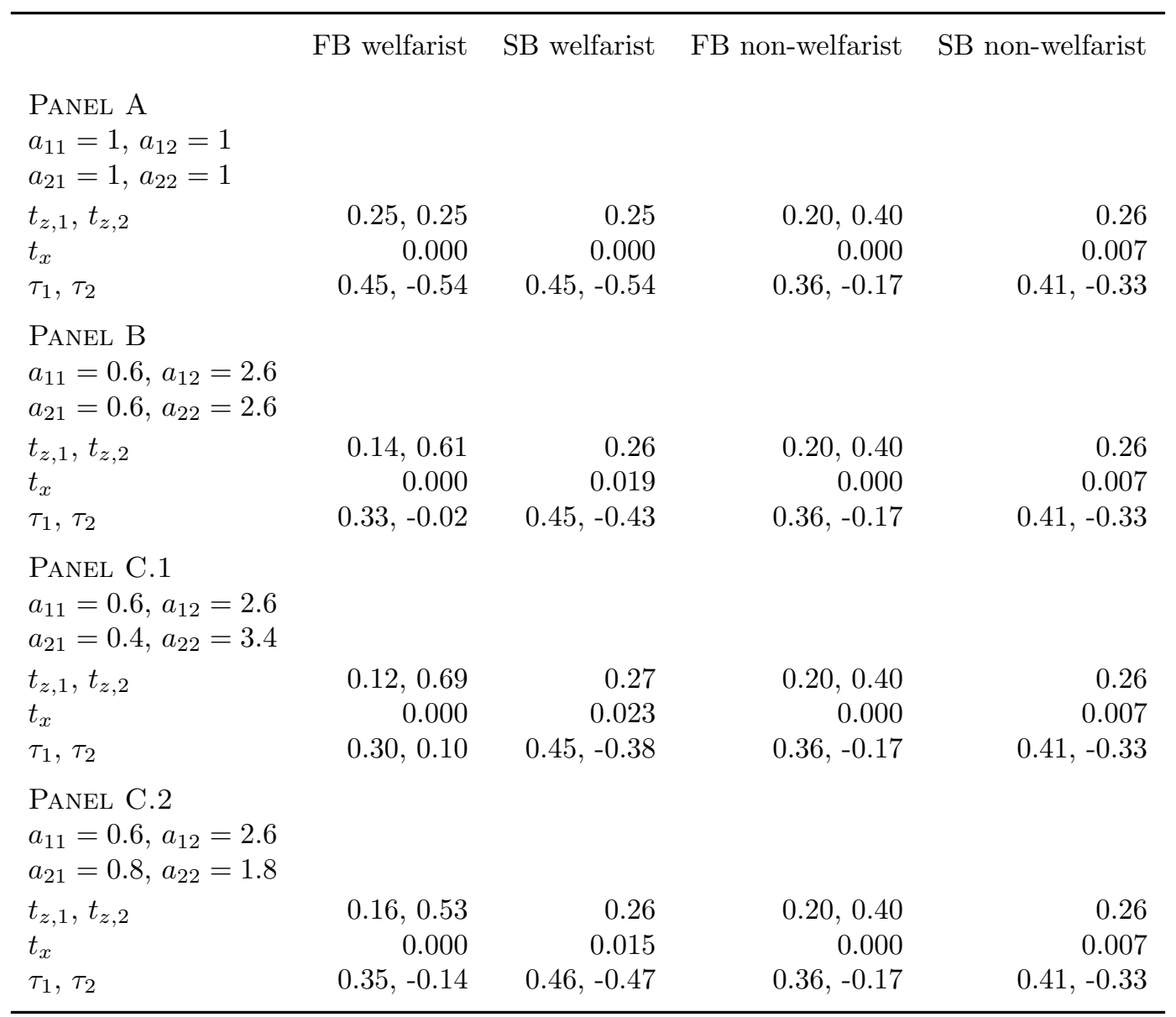

Note. FB $=$ first-best, $\mathrm{SB}=$ second-best. Except for $a_{i j}$, background parameters assume the baseline values.

Panels $\mathrm{C}$ depict situations in which type 2 households have a much stronger impact on the build up of the consumption reference level than households of type 1, that is, the externality is non-atmospheric. However, this effect is significantly more 
(significantly less) pronounced for type 2-households than for type 1-households in Panel C.1 (Panel C.2). That is, the consumption externalities are also asymmetric. The asymmetry effect may either strengthen or weaken the above result. Particularly, in Panel C.1, the primary externality generating type has a comparatively higher impact on its own type 2 than on the less positional type $1\left(a_{22}>a_{12}\right)$. Consequently, $t_{z, i}$ vary by more across household types than in case of a symmetric consumption externality. In Panel C.2, the primary externality generating type has a comparatively lower impact on its own type 2 than on the less positional type 1 $\left(a_{22}<a_{12}\right)$, with the consequence that the $t_{z, i}$ vary by less across household types than in case of a symmetric externality.

Next, consider the third column of Table 3, labeled "FB non-welfarist." Here, the tax rates on the positional good vary across households even for an atmospheric and symmetric consumption externality. In the non-welfarist case, the variation is not driven by the consumption reference levels (see Footnote 28) but by the strength of positionality, $p_{i}$. Considering the baseline values of the parameters, $p_{2}=2 p_{1}$, which - for the given preferences (50) - translates in household type 2 facing a tax rate twice as high as that of household type 1.

\subsubsection{Efficient taxation in the second-best}

The second-best results are probably of greater policy relevance than first-best tax rates. Table 3 evokes the following three insights. While the nature of the consumption externality vastly influences first-best efficient tax rates, it has only a minimal impact on second-best tax rates. This holds for both the tax rates on the positional good as well as the tax rates on the non-positional good. Although the unique second-best tax rate on the positional good mimics the first-best tax regime very incompletely only, the second-best tax rate on the non-positional good - not exceeding $2.3 \%$ - is quite low in all cases. Finally, while first-best efficient tax rates in the welfarist- and the non-welfarist cases are quite different, the respective second-best tax regimes are remarkably close to each other.

The results inferred from the above tables hold for a considerably wider set of parameter values. Sensitivity analysis with respect to $p_{i}$ and further patterns of

$a_{i j}$ (including special cases addressed in Section 3.1) are available from the authors upon request. 


\subsubsection{The fairness condition under a (non-) welfarist government}

In Section 3.3, we argue that the fairness condition rules out efficient allocations that are "too" different in terms of marginal utilities of income. Does the fairness condition under a welfarist optimality criterion rule out other allocations compared to a non-welfarist criterion? Numerical simulations suggest an affirmative answer. ${ }^{29}$ Under a non-welfarist criterion, the fairness condition systematically rules out efficient allocations that are not ruled out under a welfarist welfare criterion. ${ }^{30}$ Non-welfarism shrinks the set of fair utility allocations. Phrased differently, a non-welfarist government acts more egalitarian than a welfarist government.

In Figure 4, all parameters except for $p_{i}$ assume their baseline values. The strengths of positionality are higher here $\left(p_{1}=1 / 2, p_{2}=4 / 5\right)$ in order to make the differences between the welfarist- and the non-welfarist case better visible. In $\left(u_{1}, u_{2}\right)$ space, the figure shows the utility possibility frontiers. The thick (thin) frontier refers to the welfarist (non-welfarist) case. Along the line labeled "egalitarian allocations," $u_{1}=u_{2}$ holds. In Figure 4 , the altruism parameter is chosen to be $\varphi=5$.

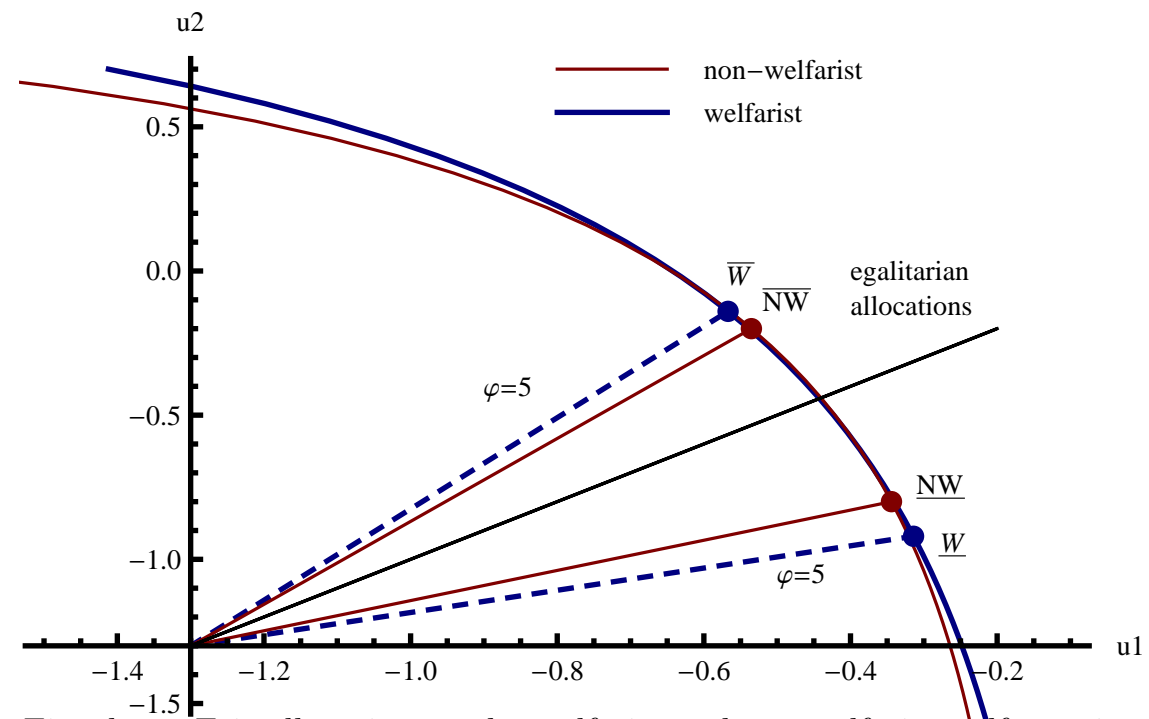

FiguRE 4. First-best: Fair allocations under welfarist and non-welfarist welfare criteria; $\varphi=5$.

The thin non-welfarist utility possibility frontier is weakly below the thick welfarist frontier. For both welfare criteria, governments respect individual preferences.

\footnotetext{
${ }^{29} \mathrm{~A}$ series of further simulations concerning the fairness condition is available from the authors upon request.

${ }^{30}$ This is a rough statement, though, as different allocations are efficient under the two welfare criteria. The following figure, however, should clarify this statement.
} 
However, for the non-welfarist criterion, the government does not take the direct externality part, $m_{i}\left(z_{i} / \bar{z}_{i}\right)$, into account.

Dots $\{\underline{W}, \bar{W}\}$ indicate the boundaries of the welfarist fair utility allocations, while dots $\{\underline{N W}, \overline{N W}\}$ indicate the boundaries of the non-welfarist fair utility allocations. As argued above, the fairness condition puts a limit on the marginal utilities of income, or equivalently, on the slopes of the utility possibility frontiers. At $\{\underline{W}, \underline{N W}\}$ as well as at $\{\bar{W}, \overline{N W}\}$ the slopes of the utility possibility frontiers are identical.

As seen in Figure 4, non-welfarism "shrinks" the set of fair utility allocations. A number of utility allocations that are fair under a welfarist welfare criterion are not considered fair under a non-welfarist welfare criterion. To gain intuition to the "shrinking" of the set of fair allocations, think about the elasticity of $\tilde{v}_{2}$ with respect to $d \tau_{1}$. The elasticity is higher in the welfarist case than in the non-welfarist case. The reason is that a non-welfarist government (in contrast to a welfarist government) does not take into account the additional change in utility, gained (lost) by type 2 from an increase (from a decrease) of the consumption of the positional good, due to the rise (a decline) of the lump sum transfer $d \tau_{1}$. In other words, the utility possibility frontier is flatter (less curved) under a welfarist criterion than under a non-welfarist criterion. So, more utility allocations are compatible with the fairness condition under a welfarist criterion as compared to a non-welfarist criterion. As a consequence, the fairness condition requires a non-welfarist government to act more egalitarian than a welfarist government.

\section{Conclusions}

This paper addresses the effects of non-atmospheric and asymmetric consumption externalities on efficient commodity taxes. The analysis is motivated by the fact that a KUJ-externality typically involves substantial preference-heterogeneities. In addition to being status conscious households are assumed to be altruistic in our framework. That is, households care about their relative position in society but, at the same time, they dislike income inequality. The analysis is conducted both from the perspective of a welfarist and a non-welfarist government. The reason is that it is questionable whether or not status preferences, which are a form of envy, should be respected by the policy maker. 
We find that the nature of the consumption externality has a strong impact on efficient first-best commodity taxes in the welfarist case. Even if a personalized lump-sum element is available, personalized commodity taxes are required to implement a first-best allocation, given the externality is non-atmospheric. Numerical simulations suggest that first-best tax rates in the welfarist case are highly sensitive to the specific nature of the consumption externality. In the non-welfarist case, personalized commodity taxes (in addition to personalized lump-sum taxes) are required to achieve a first-best allocation if, loosely speaking, some households are more status conscious than others. This implies that the nature of the consumption externality affects first-best tax rates only if the reference level has an impact on how much households are willing to give up in terms of additional status. This is the case if the marginal rate of substitution between leisure and the positional good changes with the reference level. ${ }^{31}$

Since personalized commodity taxes are hardly a feasible policy instrument we also study efficient tax programs when commodity taxes are restricted to be uniform across households. The nature of the consumption externality affects the efficient tax structure in the welfarist case insofar as the whole tax system (all commodityand lump sum taxes) are required to correct for the externality as soon as personalized commodity taxes are not available. However, our numerical simulations suggest that quantitatively these effects are only of minor relevance. Also in the non-welfarist case the whole tax system is required to correct for status preference if personalized commodity taxes are not available, but again, in the numerical simulations it turns out that these effects are small.

Perhaps surprisingly, the structures of efficient commodity tax programs of both a welfarist and a non-welfarist government are similar. Still, the motive for the taxation of status consumption is very different in the two scenarios. A welfarist government wants to tax status consumption in order to correct for a consumption externality. From the perspective of a non-welfarist government this consumption externality does not exist. Its motive for taxing status consumption is to correct for status preferences, that is, its goal is to design a tax system which induces households to behave as if they had no status concerns. Our numerical simulations

\footnotetext{
${ }^{31}$ In the section on numerical simulations we consider preferences where $\partial M R S_{z x} / \partial \bar{z}_{i}=0$, which explains why there is no effect of the nature of the consumption externality on the simulation results in the non-welfarist case.
} 
suggest that not only the qualitative structure of efficient tax programs is similar but also quantitatively efficient tax rates are surprisingly similar in the two cases.

The presence of genuine altruism has no impact on the structure of efficient commodity tax programs. However, it gives rise to a fairness condition which requires the distribution of utility not to be too unequal. The nature of the consumption externality has a strong impact on the set of allocations considered as fair. For example, in the welfarist case more inequality is tolerated towards households whose status consumption is particularly harmful. Further, we show that, everything else equal, the set of allocations considered as fair by a non-welfarist government is smaller than that considered as fair by a welfarist government, i.e. less inequality is tolerated if the government is non-welfarist. This might explain, to some extent, why governments acting rather in a non-welfarist way, such as those in Scandinavian countries, are more egalitarian, than those acting more in a welfarist way (as for example in the USA).

There are several interesting ways to extend the contribution of this paper. First, the weights $a_{i j}$ are assumed to be exogenous in this paper. A major further step consists in developing a theory that endogenizes these weights and develops a mechanism explaining how individuals form their reference groups and reference levels. Second, although redistribution is part of our model, its impact on the tax structure is limited since we allow for personalized lump-sum taxes. A further step could be to analyze efficient tax programs in the current context if the lumpsum element is restricted to be uniform. This might have a strong impact on the relationship between the fairness condition and the tax system. Third, besides genuine altruism considered in our paper, there exists other forms of altruism such as pure or paternalistic altruism (see, e.g., Johansson 1997). An interesting further step consists in studying the impact of other forms of altruism on efficient tax programs. Notwithstanding these limitations, we hope this study clarifies the impact of status effects on optimal commodity taxation and is able to contribute to future discussions of tax reform. 


\section{Appendix}

\section{Characterization of first-best allocations in the welfarist case}

The Lagrangian for the maximization problem (7)-(10) reads

$$
\begin{aligned}
\mathcal{L}= & \sum_{i=1}^{n} \theta_{i}^{F B} u_{i}\left(x_{i}, z_{i}, l_{i}, \bar{z}_{i}\right)-\sum_{i=2}^{n} \mu_{i}^{F B} \bar{u}_{i}+\lambda^{F B}\left(\sum_{i=1}^{n} w_{i}\left(1-l_{i}\right)-\sum_{i=1}^{n} x_{i}-\sum_{i=1}^{n} z_{i}\right) \\
& +\sum_{i=1}^{n} \gamma_{i}^{F B}\left(\bar{z}_{i}-\frac{1}{n} \sum_{j=1}^{n} a_{i j} z_{j}\right) .
\end{aligned}
$$

with $\theta_{i}^{F B} \equiv \mu_{i}^{F B}+\frac{\varphi}{n} \sum_{j=1}^{n} \mu_{j}^{F B}$ and $\mu_{1}^{F B} \equiv 1$. The first-order conditions with respect to $x_{i}, z_{i}, l_{i}$ and $\bar{z}_{i}$ are given by

$$
\begin{gathered}
\theta_{i}^{F B} \frac{\partial u_{i}}{\partial x_{i}}-\lambda^{F B}=0 \\
\theta_{i}^{F B} \frac{\partial u_{i}}{\partial z_{i}}-\lambda^{F B}-\frac{1}{n} \sum_{j=1}^{n} \gamma_{j}^{F B} a_{j i}=0 \\
\theta_{i}^{F B} \frac{\partial u_{i}}{\partial l_{i}}-\lambda^{F B} w_{i}=0 \\
\theta_{i}^{F B} \frac{\partial u_{i}}{\partial \bar{z}_{i}}+\gamma_{i}^{F B}=0
\end{gathered}
$$

for $i=1, \ldots, n$. Combining (53) and (52) yields equation (11) in the text and combing (52) and (54) yields equation (12) in the text.

The fairness condition in (13) can be derived as follows. From the definition for $\theta_{i}^{F B}$ it follows that

$$
\mu_{i}^{F B}=\theta_{i}^{F B}-\frac{\varphi}{n} \sum_{j=1}^{n} \mu_{j}^{F B},
$$

and hence $\sum_{i=1}^{n} \mu_{i}^{F B}=\frac{1}{1+\varphi} \sum_{i=1}^{n} \theta_{i}^{F B}$. Plug in for $\sum_{i=1}^{n} \mu_{i}^{F B}$ in (56) to get $\mu_{i}^{F B}=$ $\theta_{i}^{F B}-\frac{\varphi}{(1+\varphi) n} \sum_{j=1}^{n} \theta_{j}^{F B}$. Then the nonegativity of $\mu_{i}^{F B}$ togeter with (52) to substitute for $\theta_{i}^{F B}$ yields the fairness condition given by (13).

\section{Proof of Proposition 1}

(i) From Definition 1 we know that an externality is atmospheric if $a_{j i}=a_{j i^{\prime}}$ for all 
$j, i, i^{\prime} \in N$, whether or not the externality is asymmetric. This implies that then $\Psi_{i}=\Psi_{i^{\prime}}$ for all $i, i^{\prime} \in N$. Combining the optimality condition of the households ((4)and (5)) with those of the government ((11) and (12)) shows that households choose the optimal consumption bundle if $t_{z}^{*}=\Psi$ and $t_{x}^{*}=0$.

(ii) From Definition 1 it follows that $\Psi_{i} \neq \Psi_{i^{\prime}}$ for some $i, i^{\prime} \in N$ if the externality is non-atmospheric. This implies that personalized commodity taxes $t_{z, i}=\Psi_{i}$ are requird to induce households to choose the optimal consumption bundle.

(iii) Households differ in preferences and wages. The lump-sum element $\tau_{i}$ is adapted such that (11)-(13) hold, given that $t_{z}^{*}, t_{x}^{*}$ are set optimally.

\section{First-order condition for problem (14)-(17)}

The Lagrangian for the maximization problem (14)-(17) reads

$$
\begin{aligned}
\mathcal{L}= & \sum_{i=1}^{n} \theta_{i}^{S B} v_{i}\left(q_{x}, q_{z}, \tau_{i}, \bar{z}_{i}\right)-\sum_{i=2}^{n} \mu_{i}^{S B} \bar{v}_{i}+\lambda^{S B}\left(t_{x} \sum_{i=1}^{n} x_{i}+t_{z} \sum_{i=1}^{n} z_{i}-\sum_{i=1}^{n} \tau_{i}\right) \\
& +\sum_{i=1}^{n} \gamma_{i}^{S B}\left(\bar{z}_{i}-\frac{1}{n} \sum_{j=1}^{n} a_{i j} z_{j}\right) .
\end{aligned}
$$

The first-order conditions with respect to $t_{x}, t_{z}, \tau_{i}$ and $\bar{z}_{i}$ are given by

$$
\begin{gathered}
\sum_{i=1}^{n} \theta_{i}^{S B} \frac{\partial v_{i}}{\partial t_{x}}+\lambda^{S B}\left(\sum_{i=1}^{n} x_{i}+t_{x} \sum_{i=1}^{n} \frac{\partial x_{i}}{\partial t_{x}}+t_{z} \sum_{i=1}^{n} \frac{\partial z_{i}}{\partial t_{x}}\right)-\frac{1}{n} \sum_{i=1}^{n} \sum_{j=1}^{n} \gamma_{i}^{S B} a_{i j} \frac{\partial z_{j}}{\partial t_{x}}=0 \\
\sum_{i=1}^{n} \theta_{i}^{S B} \frac{\partial v_{i}}{\partial t_{z}}+\lambda^{S B}\left(\sum_{i=1}^{n} z_{i}+t_{x} \sum_{i=1}^{n} \frac{\partial x_{i}}{\partial t_{z}}+t_{z} \sum_{i=1}^{n} \frac{\partial z_{i}}{\partial t_{z}}\right)-\frac{1}{n} \sum_{i=1}^{n} \sum_{j=1}^{n} \gamma_{i}^{S B} a_{i j} \frac{\partial z_{j}}{\partial t_{z}}=0 \\
\theta_{i}^{S B} \frac{\partial v_{i}}{\partial \tau_{i}}+\lambda^{S B}\left(t_{x} \frac{\partial x_{i}}{\partial \tau_{i}}+t_{z} \frac{\partial z_{i}}{\partial \tau_{i}}\right)-\lambda^{S B}-\frac{1}{n} \sum_{j=1}^{n} \gamma_{j}^{S B} a_{j i} \frac{\partial z_{i}}{\partial \tau_{i}}=0 \\
\theta_{i}^{S B} \frac{\partial v_{i}}{\partial \bar{z}_{i}}+\lambda^{S B}\left(t_{x} \frac{\partial x_{i}}{\partial \bar{z}_{i}}+t_{z} \frac{\partial z_{i}}{\partial \bar{z}_{i}}\right)+\gamma_{i}^{S B}-\frac{1}{n} \sum_{j=1}^{n} \gamma_{j}^{S B} a_{j i} \frac{\partial z_{i}}{\partial \bar{z}_{i}}=0
\end{gathered}
$$

with $\theta_{i}^{S B} \equiv \mu_{i}^{S B}+\frac{\varphi}{n} \sum_{j=1}^{n} \mu_{j}^{S B}$ and $\mu_{1}^{S B} \equiv 1$. 


\section{Derivation of optimal commodity taxes in second best: welfarist case}

Take the first-order condition (59) for $t_{z}$, plug in for $\frac{\partial v_{i}}{\partial t_{z}}=-z_{i} \frac{\partial v_{i}}{\partial \tau_{i}}$ and use the definition for the net social marginal utility $b_{i} \equiv \frac{\theta_{i}^{S B}}{\lambda^{S B}} \frac{\partial v_{i}}{\partial \tau_{i}}+t_{x} \frac{\partial x_{i}}{\partial \tau_{i}}+t_{z} \frac{\partial z_{i}}{\partial \tau_{i}}-\epsilon_{i} \frac{\partial z_{i}}{\partial \tau_{i}}$ to get

$$
\begin{aligned}
& -\sum_{i=1}^{n} b_{i} z_{i}+\sum_{i=1}^{n} z_{i}+t_{x} \sum_{i=1}^{n}\left(\frac{\partial x_{i}}{\partial t_{z}}+z_{i} \frac{\partial x_{i}}{\partial \tau_{i}}\right)+t_{z} \sum_{i=1}^{n}\left(\frac{\partial z_{i}}{\partial t_{z}}+z_{i} \frac{\partial z_{i}}{\partial \tau_{i}}\right) \\
& -\sum_{i=1}^{n} \epsilon_{i}\left(\frac{\partial z_{i}}{\partial t_{z}}+z_{i} \frac{\partial z_{i}}{\partial \tau_{i}}\right)=0 .
\end{aligned}
$$

Now, make use of the Slutsky decomposition $s_{z z}^{i}=\frac{\partial z_{i}}{\partial t_{z}}+z_{i} \frac{\partial z_{i}}{\partial \tau_{i}}$ and $s_{x z}^{i}=\frac{\partial x_{i}}{\partial t_{z}}+z_{i} \frac{\partial x_{i}}{\partial \tau_{i}}$ and of the definition for the covariance $\phi(b, z)=\frac{1}{n} \sum_{i=1}^{n} b_{i} z_{i}-\bar{b} \bar{z}$ to get

$$
-\bar{b} \bar{z}+\bar{z}-\phi(b, z)=-\frac{1}{n} t_{x} \sum_{i=1}^{n} s_{x z}^{i}-\frac{1}{n} t_{z} \sum_{i=1}^{n} s_{z z}^{i}+\frac{1}{n} \sum_{i=1}^{n} \epsilon_{i} s_{z z}^{i} .
$$

Divide (63) by the average consumption of the status good $\bar{z}$ and rearrange terms to get the first part of the many-person Ramsey rule

$$
1-\bar{b}-\frac{\phi(b, z)}{\bar{z}}=\frac{-t_{x} \bar{s}_{x z}-t_{z} \bar{s}_{z z}+\frac{1}{n} \sum_{i=1}^{n} \epsilon_{i} s_{z z}^{i}}{\bar{z}} .
$$

Take the first-order condition (58) for $t_{x}$ and proceed in the same way to get the second part of the many-person Ramsey rule

$$
1-\bar{b}-\frac{\phi(b, x)}{\bar{x}}=\frac{-t_{x} \bar{s}_{x x}-t_{z} \bar{s}_{z x}+\frac{1}{n} \sum_{i=1}^{n} \epsilon_{i} s_{z x}^{i}}{\bar{x}} .
$$

With personalized lump-sum taxes available, the left-hand sides of (64) and (65) become zero as $b_{i}=\bar{b}=1$, which follows from (60), and because the covariance $\phi(b, k)=0$ with $k=\{z, x\}$, as the covariance of a variable with a constant is always zero. After rearranging terms equations, (64) and (65) can be written in matrix form as given in (19) in the text.

\section{Proof of Proposition 2}

Apply Cramer's rule to equation (19) to get (20) and (21). $t_{z}^{* *}>0$ is implied by $\epsilon_{i}>0$ together with the assumption that the $2 x 2$ sub-Slutsky matrix of the taxed goods is non-singular and negative semidefinite. 


\section{Derivation of fairness condition in second-best}

From the definition for $\theta_{i}^{S B}$ it follows that

$$
\mu_{i}^{S B}=\theta_{i}^{S B}-\frac{\varphi}{n} \sum_{j=1}^{n} \mu_{j}^{S B}
$$

and hence $\sum_{i=1}^{n} \mu_{i}^{S B}=\frac{1}{1+\varphi} \sum_{i=1}^{n} \theta_{i}^{S B}$. Plug in for $\sum_{i=1}^{n} \mu_{i}^{F B}$ in (66) to get $\mu_{i}^{S B}=$ $\theta_{i}^{S B}-\frac{\varphi}{(1+\varphi) n} \sum_{j=1}^{n} \theta_{j}^{S B}$. Then the nonegativity of $\mu_{i}^{S B}$ togeter with (60) to substitute for $\theta_{i}^{S B}$ yields the fairness condition given by (29).

\section{Characterization of first-best allocations in the non-welfarist case}

The Lagrangian for the maximization problem (34)-(37) reads

$$
\mathcal{L}=\sum_{i=1}^{n} \tilde{\theta}_{i}^{F B} \tilde{u}_{i}\left(x_{i}, z_{i}, l_{i}\right)-\sum_{i=2}^{n} \tilde{\mu}_{i}^{F B} \bar{u}_{i}+\tilde{\lambda}^{F B}\left(\sum_{i=1}^{n} w_{i}\left(1-l_{i}\right)-\sum_{i=1}^{n} x_{i}-\sum_{i=1}^{n} z_{i}\right)
$$

with $\tilde{\theta}_{i}^{F B} \equiv \tilde{\mu}_{i}^{F B}+\frac{\varphi}{n} \sum_{j=1}^{n} \tilde{\mu}_{j}^{F B}$ and $\tilde{\mu}_{1}^{F B} \equiv 1$. The first-order conditions with respect to $x_{i}, z_{i}, l_{i}$ are given by

$$
\begin{gathered}
\tilde{\theta}_{i}^{F B} \frac{\partial u_{i}}{\partial x_{i}}-\tilde{\lambda}^{F B}=0 \\
\tilde{\theta}_{i}^{F B} \frac{\partial u_{i}}{\partial z_{i}}-\tilde{\lambda}^{F B}=0 \\
\tilde{\theta}_{i}^{F B} \frac{\partial u_{i}}{\partial l_{i}}-\tilde{\lambda}^{F B} w_{i}=0
\end{gathered}
$$

for $i=1, \ldots, n$. Combining (69) and (68) yields equation (38) in the text and combing (68) and (70) yields equation (39) in the text. The fairness condition in (40) can be derived in the same way as the one in the welfarist case.

\section{Proof of Proposition 4}

(i) Since households differ in preferences and wages they are in general willing to give up different amounts of good $x$ for the better relative position an additional unit of good $z$ provides, i.e. $\Psi_{i} \neq \Psi_{i^{\prime}}$ for some $i, i^{\prime} \in N$ no matter whether the externality is atmospheric or not. Combining the optimality condition of the households 
((31)and (32)) with those of the government ((38) and (39)) shows that households choose the optimal consumption bundle if $\tilde{t}_{z}^{i}=\tilde{\Psi}_{i}$ and $\tilde{t}_{x}^{*}=0$.

(ii) If the externality is symmetric and $m_{r} / \tilde{u}_{x}$ is the same for all households, then $\tilde{\Psi}_{i}=\tilde{\Psi}_{i^{\prime}}$ for all $i, i^{\prime} \in N$. Combining the optimality condition of the households ((31)and (32)) with those of the government ((38) and (39)) shows that households choose the optimal consumption bundle if $\tilde{t}_{z}^{*}=\tilde{\Psi}$ and $\tilde{t}_{x}^{*}=0$. However, a uniform tax on the status good is only sufficient to implement a first-best allocation if in addition the externality is atmospheric. As soon as the externality is non-atmospheric a personalized commodity tax is required to implement a first-best allocation even if the externality is symmetric and $m_{r} / \tilde{u}_{x}$ is the same for all households. The reason is that then the indirect effect of the reference level on social welfare (which is zero in first best) can not be fully internalized.

(iii) If $\partial M R S_{z x} / \partial \bar{z}_{i}=0$ then the correction term $\tilde{\Psi}_{i}$ is independent of $\bar{z}_{i}$.

(iv) Households differ in preferences and wages. The lump-sum element $\tau_{i}$ is adapted such that (11)-(13) hold, given that $\tilde{t}_{z}^{*}, \tilde{t}_{x}^{*}$ are set optimally.

\section{First-order condition for problem (41)-(44)}

The Lagrangian for the maximization problem (41)-(44) reads

$$
\begin{aligned}
\mathcal{L}= & \sum_{i=1}^{n} \tilde{\theta}_{i}^{S B} \tilde{v}_{i}\left(q_{x}, q_{z}, \tau_{i}, \bar{z}_{i}\right)-\sum_{i=2}^{n} \tilde{\mu}_{i}^{S B} \bar{v}_{i}+\tilde{\lambda}^{S B}\left(t_{x} \sum_{i=1}^{n} x_{i}+t_{z} \sum_{i=1}^{n} z_{i}-\sum_{i=1}^{n} \tau_{i}\right) \\
& +\sum_{i=1}^{n} \tilde{\gamma}_{i}^{S B}\left(\bar{z}_{i}-\frac{1}{n} \sum_{j=1}^{n} a_{i j} z_{j}\right) .
\end{aligned}
$$

The first-order conditions with respect to $t_{x}, t_{z}, \tau_{i}$ and $\bar{z}_{i}$ are given by

$$
\begin{gathered}
\sum_{i=1}^{n} \tilde{\theta}_{i}^{S B} \frac{\partial \tilde{v}_{i}}{\partial t_{x}}+\tilde{\lambda}^{S B}\left(\sum_{i=1}^{n} x_{i}+t_{x} \sum_{i=1}^{n} \frac{\partial x_{i}}{\partial t_{x}}+t_{z} \sum_{i=1}^{n} \frac{\partial z_{i}}{\partial t_{x}}\right)-\frac{1}{n} \sum_{i=1}^{n} \sum_{j=1}^{n} \tilde{\gamma}_{i}^{S B} a_{i j} \frac{\partial z_{j}}{\partial t_{x}}=0 \\
\sum_{i=1}^{n} \tilde{\theta}_{i}^{S B} \frac{\partial \tilde{v}_{i}}{\partial t_{z}}+\tilde{\lambda}^{S B}\left(\sum_{i=1}^{n} z_{i}+t_{x} \sum_{i=1}^{n} \frac{\partial x_{i}}{\partial t_{z}}+t_{z} \sum_{i=1}^{n} \frac{\partial z_{i}}{\partial t_{z}}\right)-\frac{1}{n} \sum_{i=1}^{n} \sum_{j=1}^{n} \tilde{\gamma}_{i}^{S B} a_{i j} \frac{\partial z_{j}}{\partial t_{z}}=0 \\
\tilde{\theta}_{i}^{S B} \frac{\partial \tilde{v}_{i}}{\partial \tau_{i}}+\tilde{\lambda}^{S B}\left(t_{x} \frac{\partial x_{i}}{\partial \tau_{i}}+t_{z} \frac{\partial z_{i}}{\partial \tau_{i}}\right)-\tilde{\lambda}^{S B}-\frac{1}{n} \sum_{j=1}^{n} \tilde{\gamma}_{j}^{S B} a_{j i} \frac{\partial z_{i}}{\partial \tau_{i}}=0 \\
\tilde{\theta}_{i}^{S B} \frac{\partial \tilde{v}_{i}}{\partial \bar{z}_{i}}+\tilde{\lambda}^{S B}\left(t_{x} \frac{\partial x_{i}}{\partial \bar{z}_{i}}+t_{z} \frac{\partial z_{i}}{\partial \bar{z}_{i}}\right)+\tilde{\gamma}_{i}^{S B}-\frac{1}{n} \sum_{j=1}^{n} \tilde{\gamma}_{j}^{S B} a_{j i} \frac{\partial z_{i}}{\partial \bar{z}_{i}}=0
\end{gathered}
$$


with $\tilde{\theta}_{i}^{S B} \equiv \tilde{\mu}_{i}^{S B}+\frac{\varphi}{n} \sum_{j=1}^{n} \tilde{\mu}_{j}^{S B}$ and $\tilde{\mu}_{1}^{S B} \equiv 1$.

\section{Proof of Proposition 5}

Take (73) and plug in for Roy's identity $\frac{\partial \tilde{v}_{i}}{\partial t_{z}}=-z_{i} \frac{\partial \tilde{v}_{i}}{\partial \tau_{i}}-\left(\frac{\partial s_{i}}{\partial t_{z}}+z_{i} \frac{\partial s_{i}}{\partial \tau_{i}}\right)$ to get

$$
\begin{aligned}
& \tilde{\lambda}^{S B}\left(\sum_{i=1}^{n} z_{i}+t_{x} \sum_{i=1}^{n} \frac{\partial x_{i}}{\partial t_{z}}+t_{z} \sum_{i=1}^{n} \frac{\partial z_{i}}{\partial t_{z}}\right)=\sum_{i=1}^{n} \tilde{\theta}_{i}^{S B} \frac{\partial \tilde{v}_{i}}{\partial \tau_{i}} z_{i}+\sum_{i=1}^{n} \tilde{\theta}_{i}^{S B}\left(\frac{\partial s_{i}}{\partial t_{z}}+z_{i} \frac{\partial s_{i}}{\partial \tau_{i}}\right) \\
& +\frac{1}{n} \sum_{i=1}^{n} \sum_{j=1}^{n} \tilde{\gamma}_{i} a_{i j} \frac{\partial z_{j}}{\partial t_{z}}
\end{aligned}
$$

Next, take (74) and multiply it with $z_{i}$. Then plug in for $\tilde{\theta}_{i}^{S B} \frac{\partial \tilde{v}_{i}}{\partial \tau_{i}} z_{i}$ from (74) into (76) and use the Slutsky decomposition $s_{z z}^{i}=\frac{\partial z_{i}}{\partial t_{z}}+z_{i} \frac{\partial z_{i}}{\partial \tau_{i}}$ and $s_{x z}^{i}=\frac{\partial x_{i}}{\partial t_{z}}+z_{i} \frac{\partial x_{i}}{\partial \tau_{i}}$ to get

$$
t_{x} \sum_{i=1}^{n} s_{x z}^{i}+t_{z} \sum_{i=1}^{n} s_{z z}^{i}=\sum_{i=1}^{n} \frac{\tilde{\theta}_{i}^{S B}}{\tilde{\lambda} S B}\left(\frac{\partial s_{i}}{\partial t_{z}}+z_{i} \frac{\partial s_{i}}{\partial \tau_{i}}\right)+\frac{1}{n} \sum_{i=1}^{n} \sum_{j=1}^{n} \frac{\tilde{\gamma}_{i}^{S B}}{\tilde{\lambda} S B} a_{j i} s_{z z}^{i}
$$

Apply the same steps to the first order condition for $t_{x}$ given by (72) to get

$$
t_{x} \sum_{i=1}^{n} s_{x x}^{i}+t_{z} \sum_{i=1}^{n} s_{z x}^{i}=\sum_{i=1}^{n} \frac{\tilde{\theta}_{i}^{S B}}{\tilde{\lambda}^{S B}}\left(\frac{\partial s_{i}}{\partial t_{x}}+x_{i} \frac{\partial s_{i}}{\partial \tau_{i}}\right)+\frac{1}{n} \sum_{i=1}^{n} \sum_{j=1}^{n} \frac{\tilde{\gamma}_{i}^{S B}}{\tilde{\lambda}^{S B}} a_{j i} s_{z x}^{i} .
$$

Finally, apply Cramer's rule to the system of equations given by (77) and (78) and substitute for $\left(\frac{\partial s_{i}}{\partial t_{k}}+k_{i} \frac{\partial s_{i}}{\partial \tau_{i}}\right)=\frac{1}{\bar{z}_{i}} \frac{\partial m_{i}}{\partial r_{i}} s_{z k}$ with $k=x, z$ to get (45) and (46).

\section{Proof of Corollary 2}

(i) It follows from (45) and (46) that $t_{z}^{* *}=\frac{\tilde{\theta}^{S B}}{\tilde{\lambda}^{S B}} \frac{1}{\bar{z}} \frac{\partial m}{\partial r}+\tilde{\epsilon}_{i}$ and $t_{x}^{* *}=0$ if the externality is atmospheric and symmetric and if $\frac{\tilde{\theta}_{i}^{S B}}{\tilde{\lambda}^{S B}} \frac{\partial m_{i}}{\partial r_{i}}=\frac{\tilde{\theta}^{S B}}{\tilde{\lambda}^{S B}} \frac{\partial m}{\partial r}$ for all $i \in N$. To see that in this case $\tilde{\epsilon}_{i}=\tilde{\epsilon}=0$ for all $i \in N$ in the optimum, take the first order condition for $\bar{z}_{i}$ given by $(75)$ which can also be written as

$$
\frac{\tilde{\gamma}_{i}^{S B}}{\tilde{\lambda} S B}=-\frac{\tilde{\theta}_{i}^{S B}}{\tilde{\lambda} S B} \frac{\partial \tilde{v}_{i}}{\partial \bar{z}_{i}}-t_{x} \frac{\partial x_{i}}{\partial \bar{z}_{i}}-t_{z} \frac{\partial z_{i}}{\partial \bar{z}_{i}}+\tilde{\epsilon}_{i} \frac{\partial z_{i}}{\partial \bar{z}_{i}} .
$$

Use $\frac{\partial \tilde{v}_{i}}{\partial \bar{z}_{i}}=-\frac{1}{\bar{z}_{i}} \frac{\partial m_{i}}{\partial r_{i}} \frac{\partial z_{i}}{\partial \bar{z}_{i}}$ and plug in for $t_{z}^{* *}$ and $t_{x}^{* *}$ as given above. Then one can see that $\tilde{\gamma}_{i}^{S B}=0$ for all $i \in N$, and consequently $\tilde{\epsilon}_{i}=\tilde{\epsilon}=0$ in the optimum. This implies that under the condition in Corollary (i) optimal commodity tax rates are given by (47).

(ii) Follows immediately from (45) and (46). 


\section{References}

[1] Abel, A.B. (1999), Risk premia and term premia in general equilibrium, Journal of Monetary Economics 43, 3-33.

[2] Alpizar, F., F. Carlsson, O. Johansson-Stenman (2005), How much do we care about absolute versus relative income and consumption?, Journal of Economic Behavior \&5 Organization 56, 405-421.

[3] Alvarez-Cuadrado, F., J.M. Casado, J.M. Labeaga, D. Sutthiphisal (2012), Envy and habits: panel data estimates of interdependent preferences, Banco de Espana Working Paper 1213, available at SSRN: http : //ssrn. com/abstract=2014005.

[4] Alvarez-Cuadrado, F., and N. Van Long (2011), Relative consumption and renewable resource extraction under alternative property-rights regimes, Resource and Energy Economics 33, 1028-1053.

[5] Aronsson, T., O. Johansson-Stenman, (2008) When the Joneses' consumption hurts: optimal public good provision and nonlinear income taxation, Journal of Public Economics 92, 986 - 997.

[6] Aronsson, T., O. Johansson-Stenman, (2010) Positional concerns in an OLG model: optimal labor and capital income taxation, International Economic Review 51, 1071-1095.

[7] Besley, T. (1988), A simple model for merit good arguments, Journal of Public Economics 35, 371-383.

[8] Blomquist, S., L. Micheletto (2006), Optimal redistributive taxation when governments' and agents' preferences differ, Journal of Public Economics 90, 12151233.

[9] Boskin, M.J., E. Sheshinsky, (1978) Optimal redistributive taxation when individual welfare depends upon relative income, Quarterly Journal of Economics $92,589-601$.

[10] Brekke, K.A., R.B. Howarth (2002), Status, growth and the environment. Goods as symbols in applied welfare economics, Cheltenham: Edward Elgar. 
[11] Campbell, C., and J. Cochrane (1999), By force of habit: A consumption-based explanation of aggregate stock market behavior, Journal of Political Economy 107, 205-251.

[12] Carroll, C.D., J. Overland, and D.N. Weil (1997), Comparison utility in a growth model, Journal of Economic Growth 2, 339-367.

[13] Cowan, R., W. Cowan, G.M.P. Swann (2004), Waves in consumption with interdependence among consumers, Canadian Journal of Economics 37, 149177.

[14] Diamond, P. (1973), Consumption externalities and imperfect corrective pricing, Bell Journal of Economics and Management Science 4, 526-538.

[15] Dupor, B., W.F. Liu (2003), Jealousy and equilibrium overconsumption, American Economic Review 93, 423-428.

[16] Easterlin, R.A. (1995) Will raising the incomes of all increase the happiness of all?, Journal of Economic Behavior \& Organization 27, 35-47.

[17] Eckerstorfer, P. (2013), Relative consumption concerns and the optimal tax mix, Journal of Public Economic Theory, forthcoming.

[18] Fehr, E., K. Schmidt (1999), A theory of fairness, competition, and cooperation, Quarterly Journal of Economics 114, 817-868.

[19] Ferrer-I-Carbonell, A. (2005), Income and well-being: An empirical analysis of the comparison income effect, Journal of Public Economics 89, 997-1019.

[20] Frank, R.H. (1985), Choosing the right pond. Human behavior and the quest for status. New York: Oxford University Press.

[21] Frank, R.H. (1999), Luxury fever. Why money fails to satisfy in an era of excess. New York: The Free Press.

[22] , J. , E. Sheshinski (1976), Direct versus indirect remedies for externalities, Journal of Political Economy 84, 797-808. 
[23] Harsanyi, J. (1982), Morality and the theory of rational behaviour. in: A. Sen and B. Williams (eds), Utilitarianism and Beyond, Cambridge: Cambridge University Press.

[24] Johansson-Stenman, O. (1997), Optimal pigovian taxes under altruism, Land Economics 73, 297-308.

[25] Johansson-Stenman, O. (2005), Global environmental problems, efficiency and limited altruism, Economics Letters 86, 101-106.

[26] Johansson-Stenman, O., F. Carlsson, D. Daruvala (2002), Measuring future grandparents' preferences for equality and relative standing, Economic Journal $112,362-383$.

[27] Johansson-Stenman, O., P. Martinsson (2006), Honestly, why are you driving a BMW?, Journal of Economic Behavior \& Organization 60, 129-146.

[28] Layard, R. (1980), Human satisfactions and public policy, Economic Journal $90,737-750$.

[29] Kanbur, R., J. Pirtill, M. Tuomala (2006), Non-welfarist optimal taxation and behavioral public economics, Journal of Economic Surveys 20, 849-868.

[30] Liu, W.F., S.J. Turnovsky (2005), Consumption externalities, production externalities, and long-run macroeconomic efficiency, Journal of Public Economics 89, 1097-1129.

[31] Ljungqvist, L., H. Uhlig (2000), Tax policy and aggregate demand management under catching up with the Joneses, American Economic Review 90, 356-366.

[32] Long, N.V., F. Alvarez-Cuadrado (2013), Envy and inequality, Scandinavian Journal of Economics, forthcoming.

[33] Luttmer, E.F.P. (2005), Neighbors as negatives: Relative earnings and wellbeing, Quarterly Journal of Economics 120, 963-1002.

[34] Maurer, J., A. Meier (2008), Smooth it Like the 'Joneses'? Estimating peergroup effects in intertemporal consumption choice, Economic Journal 118, 454476. 
[35] McBride, M. (2001), Relative-income effects on subjective well-being in the cross-section, Journal of Economic Behavior $\& 3$ Organization 45, 251-278.

[36] Micheletto, L. (2008), Redistribution and the optimal mixed taxation in the presence of consumption externalities, Journal of Public Economics 92, 22622274 .

[37] Neumark, D., A. Postlewaite (1998), Relative income concerns and the rise in married women's employment, Journal of Public Economics 70, 157-183.

[38] O'Donoghue, T., M. Rabin (2006), Optimal sin taxes, Journal of Public Economics 90, 1825-1849.

[39] Ravina, E. (2007), Habit persistence and keeping up with the Joneses: evidence from micro data, available at SSRN: http://ssrn.com/abstract=928248.

[40] Sandmo, A. (1975), Optimal taxation in the presence of externalities, Swedish Journal of Economics 77, 86-98.

[41] Sandmo, A. (1976), Direct versus indirect Pigovian taxation, European Economic Review 7, 337-349.

[42] Scitovsky, T. (1992), The joyless economy. The psychology of human satisfaction. New York and Oxford: Oxford University Press.

[43] Solnik, S.J., D. Hemenway (1998), Is more always better? A survey on positional concerns, Journal of Economic Behavior \&3 Organization 37, 373-383.

[44] Solnik, S.J., D. Hemenway (2005), Are positional concerns stronger in some domains than in others?, American Economic Review 95, 147-151.

[45] Wendner, R., L.H. Goulder (2008), Status effects, public goods provision, and excess burden, Journal of Public Economics 92, 1968-1985.

[46] Wendner, R. (2013), Ramsey, Pigou, heterogeneous agents, and nonatmospheric consumption externalities, Journal of Public Economic Theory, forthcoming. 